\title{
Hydrological and runoff formation processes based on isotope tracing during ablation period in the source regions of Yangtze River
}

\author{
Zong-Jie Li ${ }^{1}$, Zong-Xing $\mathrm{Li}^{2}$, Ling-Ling Song ${ }^{3}$, Juan Gui ${ }^{2}$, Jian Xue ${ }^{2}$, Bai Juan Zhang ${ }^{1}$, and Wen De Gao ${ }^{1}$ \\ ${ }^{1}$ College of Energy and Power Engineering, Lanzhou University of Technology, Lanzhou 730050, China \\ ${ }^{2}$ Observation and Research Station of Eco-Hydrology and Environmental Protection by Stable Isotope Tracing \\ in High and Cold Mountainous Areas/Key Laboratory of Ecohydrology of Inland River Basin/Gansu Qilian Mountains \\ Ecology Research Center, Northwest Institute of Eco-Environment and Resources, Chinese Academy of Sciences, \\ Lanzhou 730000, China \\ ${ }^{3}$ College of Forestry, Gansu Agricultural University, Lanzhou, Gansu 730070, China
}

Correspondence: Zong-Jie Li (lzjie314@163.com) and Zong-Xing Li (lizxhhs@ 163.com)

Received: 7 October 2019 - Discussion started: 22 October 2019

Revised: 24 April 2020 - Accepted: 2 July 2020 - Published: 26 August 2020

\begin{abstract}
This study focused on the hydrological and runoff formation processes of river water by using stable isotope tracing in the source regions of the Yangtze River during different ablation episodes in 2016 and the ablation period from 2016 to 2018. The effects of altitude on stable isotope characteristics for the river in the glacier permafrost area were greater than for the main stream and the permafrost area during the ablation period in 2016. There was a significant negative correlation (at the 0.01 level) between precipitation and $\delta^{18} \mathrm{O}$, while a significant positive correlation was evident between precipitation and $d$-excess. More interestingly, significant negative correlations appeared between $\delta^{18} \mathrm{O}$ and temperature, relative humidity, and evaporation. A mixed segmentation model for end-members was used to determine the proportion of the contributions of different water sources to the target water body. The proportions of precipitation, supra-permafrost water, and glacier and snow meltwater for the main stream were $41.70 \%$, $40.88 \%$, and $17.42 \%$, respectively. The proportions of precipitation, supra-permafrost water, and glacier and snow meltwater were $33.63 \%, 42.21 \%$, and $24.16 \%$ for the river in the glacier permafrost area and $20.79 \%, 69.54 \%$, and $9.67 \%$, respectively, for that in the permafrost area. The supra-permafrost water was relatively stable during the different ablation periods, becoming the main source of runoff
\end{abstract}

in the alpine region, except for precipitation, during the ablation period.

\section{Introduction}

Liquid precipitation, glaciers, snow, and permafrost in cold regions are important components of hydrological processes, serve as a key link in the water cycle, and are amplifiers and indicators of climate change (Yang et al., 2012; Chang et al., 2015; Li et al., 2016a, b; 2018). They are not only important as the recharge sources of water in river basins but are also important resources to support regional development (Halder et al., 2015; Lafrenière and Lamoureux, 2019). The temporal and spatial variations in runoff components are of great significance for water levels during wet and dry years in terms of ecological protection and the distribution of water resources (Wang et al., 2012; Pan et al., 2017; Mu et al., 2018). Therefore, the study on the composition change of runoff and its hydrological effect in cold areas can not only consolidate theories on runoff research, prediction, and adaptation, but also have important practical significance for construction, industry, and agriculture in cold regions (Wang et al., 2009, 2017, 2019).

The stable isotope tracer technique has become an important research method in hydrology. In recent years, the re- 
sponse of hydrological processes to climate change in cold regions has become a hot topic in the field of global change, which has greatly promoted the application of the stable isotope and chemical ion tracing methods in the analysis of runoff in cold regions ( $\mathrm{Li}$ et al., 2015, 2019; Qu et al., 2017; Zhu et al., 2019). Liu et al. (2004) systematically studied the contribution of glacier and snow meltwater to runoff in a cold area in Colorado, USA. It was found that the contribution of glacier and snow meltwater to runoff in spring was as high as $82 \%$. Boucher and Carey (2010) systematically studied runoff segmentation in permafrost basins. Maurya et al. (2011) found that the average contribution of meltwater to runoff was $32 \%$ in typical glacial basins on the southern slope of the Himalayas. The application of the stable isotope tracer method in the analysis of runoff components in the cold regions of China has been relatively small. Gu and Longinelli (1993) first used $\delta^{18} \mathrm{O}$ as a tracer in the Urumqi River in the Tian Shan. The recharge water source can be separated into rainfall, snow meltwater, groundwater, and ice meltwater. The results showed that groundwater and snow meltwater were the major recharge sources of the Urumqi River in different periods and locations. Since then, Kong and Pang (2012) have studied the contribution of meltwater to runoff and its climatic sensitivity in two typical glacial basins in the Tian Shan. The composition of runoff from the Tizinafu River in the Tian Shan shows that the average contribution of snow meltwater is $43 \%$ (Fan et al., 2015). The contribution of glacier and snow meltwater to runoff in the Baishui River in the Jade Dragon Snow Mountains was $53.4 \%$ in summer (Pu et al., 2013). A study of the Babao River and the Hulugou basin in the Qilian Mountains showed that different water sources were fully mixed into groundwater before recharging rivers in this cold alpine region and that the contribution of meltwater in the cryosphere to runoff in the cold region was as high as 33\% (Li et al., 2014a, b). Although these studies determined the contribution of precipitation and glacier and snow meltwater to runoff in the cold regions, they neglected the contribution of supra-permafrost water to runoff and its impact on hydrological processes (Prasch et al., 2013; Lutz et al., 2014). On the one hand, it increases the uncertainty of runoff analysis in the cold regions. On the other hand, it is difficult to comprehensively evaluate the impact of components on the runoff process and the hydrological effects in cold regions.

The source of the Yangtze River, which is a typical alpine frozen soil area, is an important ecological barrier and a protected water source in China (Liang et al., 2008; Li et al., 2017). The regional climate shows a significant warm and wet trend against the background of global climate change. So regional evapotranspiration increases and ice and snow resources exhibit an accelerating melting trend (Kang et al., 2007; Wang et al., 2019). The increase in ground temperature can cause ice and snow resources to melt significantly. The active layer becomes thicker and degenerates remarkably (Shi et al., 2019). Given this background, the tempo- ral and spatial patterns, mechanisms, and influences of precipitation, glacier and snow meltwater, meltwater in the active layer, and groundwater in the region undergo profound changes and impact runoff processes (Wu et al., 2015). These significant impacts and their hydrological effects on the entire basin have gradually become prominent.

In summary, due to the lack of data and the difficulty of observation and sampling in cold regions, current studies have paid more attention to the study of hydrological processes and water cycle characteristics at the watershed scale from the macroscopic point of view. However, there is a lack of in-depth study on the mechanism of the temporal and spatial variations in runoff components from the microscopic point of view, and the understanding of its hydrological effects is still in the exploratory stage. At present, although stable isotope tracer techniques have been applied to the analysis of runoff in cold regions, most of the current studies are limited to the assessment of the contribution and impact of glacier and snow meltwater but neglect the significant role of liquid precipitation increase and meltwater in the active layer. These results in a lack of systematic understanding of the hydrological effects of runoff composition changes in cold regions. Meanwhile, different types of tributaries in runoffproducing areas are the key to runoff-producing processes and are the main links to understanding hydrological processes in cold regions. It is urgent to develop an understanding of how runoff is produced. In addition, the current study of hydrological processes in the source area of the Yangtze River focuses on the variation in runoff itself and its response mechanism to climate change, lacking in-depth analysis of runoff components and its hydrological effects. Therefore, taking the source area of the Yangtze River as an example, we conduct a study into the temporal and spatial variations in isotopes in different tributary rivers under the background of climate warming and their influencing factors by using the methods of field observation, experimental testing, stable isotope tracing, and analytical modeling of end-element mixed runoff. Based on the conversion signals of stable isotopes in each link of the runoff process, at first, this study further explores the hydraulic relations, recharge-drainage relations and their transformation paths, and the processes of each water body. Furthermore, this study determines the composition of runoff and quantifies the contribution of each runoff component to different types of tributaries. Finally, this study analyzes the hydrological effects of the temporal and spatial variation in runoff components. On the one hand, the research results can reveal the evolution mechanism of runoff in cold regions under the background of climate warming. On the other hand, it provides parameter support and a theoretical basis for the simulation and prediction of runoff changes in cold regions. Then it provides a scientific basis for a more systematic understanding of the hydrological effects caused by underlying surface changes in cold regions, ultimately providing decision-making basis for the ra- 
tional development and utilization of water resources in river basins.

\section{Data and methods}

\subsection{Study area}

The source region of the Yangtze River is located in the hinterland of the Tibetan Plateau (Fig. 1). It is an important ecological barrier and water conservation region in China. The southern boundaries are the Tanggula Mountains and Sederi Peak, which contain the watersheds of the Salween River and Lantsang River, respectively. The mean altitude reaches $4000 \mathrm{~m}$ above sea level with a decreasing elevation from west to east (Yu et al., 2013) that covers an area of approximately $138000 \mathrm{~km}^{2}, 7.8 \%$ of the total area of the Yangtze River basin. Most tributaries start from glaciers and form very dense drainage networks, such as those of the Chumaer River in the north, Tuotuo River in the middle, and Dangqu River in the south (Pu, 1994). The glaciers in the study area are mainly distributed along the north-oriented slopes of the Tanggula Mountains and Sedir Mountains and the southoriented slopes of the Kunlun Mountains, with a total area of $1496.04 \mathrm{~km}^{2}$ (Yao et al., 2014). The permafrost has a thickness of 10-120 m, which accounts for $77 \%$ of the total basin area, and most surface soils are frozen during winter and thaw in summer. Active layer thicknesses range from 1 to $4 \mathrm{~m}$ (Gao et al., 2012). Annual average temperatures range from 3 to $5.5^{\circ} \mathrm{C}$. The annual precipitation is $221.5-515 \mathrm{~mm}$ (Yu et al., 2014). The mean annual precipitation varies considerably over the reserve, and $80 \%$ of the annual precipitation occurs during summer, with the highest precipitation occurring in August.

\subsection{Sample collection}

This study mainly collects precipitation, glacier and snow meltwater, supra-permafrost water, and river water to systematically analyze the recharge relationship between precipitation, glacier and snow meltwater, supra-permafrost water, and river water in the source area of the Yangtze River. In this study, the initial ablation period is from May to June, the strong ablation period is from July to August, and the end ablation period is from September to October. In order to analyze the influence of meteorological factors on the stable isotope in river water, samples were collected once per week at the Zhimenda Hydrological Station (ZMD) and Tuotuo River Meteorological Station (TTH) throughout the sampling period. A total of 201 river water samples were collected in this study. The specific sampling process is as follows.

River water. In order to analyze the spatial and temporal characteristics of stable isotopes of river water in the main stream (25 samples) and major tributary (including rivers in glacier permafrost area (105 samples) and rivers in permafrost area (167 samples)) in the study area, all river water samples around the traffic routes in the source area of the Yangtze River were collected in initial ablation in 2016 (48 samples), ablation in 2016 ( 88 samples), end ablation in 2016 (45 samples), ablation in 2017 (55 samples), and ablation in 2018 (61 samples) (Fig. 1).

Glacier and snow meltwater. This paper researched the hydrochemistry characteristic of meltwater in the cryosphere (Yuzhu peak glacier, Geladandong glacier, and Dongkemadi glacier) through collected water samples by fixed-point sampling from June to September in 2016 and 2017. The samples were collected once every $10 \mathrm{~d}$ at the glacier front during the ablation period. The sampling time is at $14: 00 \mathrm{UTC}+8$ every day. The sampling location is in the hydrological section at the end of the glacier.

Supra-permafrost water. Supra-permafrost water is the most widely distributed groundwater type in the source region of the Yangtze River, and it is mainly stored in the permafrost active layer (Li et al., 2018). For hydrochemistry characteristics of supra-permafrost water in the study area, this paper collected water samples by comprehensive sampling from June to September in 2016 and 2018. The sampling process was manual. At first, a $2 \mathrm{~m}$ deep profile of the permafrost active layer was dug at each of the sampling points. Then, the water samples were immediately filtered with $0.45 \mu \mathrm{m}$ Millipore filtration membrane. Then, samples were poured into a clean polyethylene bottle.

Precipitation. precipitation samples were collected at Zhimenda Hydrological Station (ZMD) at the mountain pass of the source area of the Yangtze River, Qumalai Meteorological Station (QML) in the middle reaches of the source area, and Tuotuo River Meteorological Station (TTH) in the upper reaches of the source area. The sampling period extended from 1 April 2016 to 31 October 2018.

Before analysis, all samples were stored at $4{ }^{\circ} \mathrm{C}$ in a refrigerator without evaporation. Precipitation and surface water samples were analyzed for $\delta^{18} \mathrm{O}$ and $\delta \mathrm{D}$ by means of laser absorption spectroscopy (liquid water isotope analyzer, Los Gatos Research DEL-100, USA) at the Key Laboratory of Ecohydrology of Inland River Basin, Northwest Institute of Eco-Environment and Resources, CAS. The results are reported relative to the Vienna Standard Mean Ocean Water (VSMOW). Measurement precisions for $\delta^{18} \mathrm{O}$ and $\delta \mathrm{D}$ were better than $0.5 \%$ and $0.2 \%$, respectively. Field measurements included $\mathrm{pH}$, dissolved oxygen (DO), electrical conductivity (EC), and water temperature.

\subsection{End-member mixing analysis}

Hooper (2003) introduced the end-member mixing analysis (EMMA) using chemical/isotopic compositions in water. The techniques involve graphical analyses, in which chemical and isotopic parameters are used to represent the designated end-members. Tracer concentrations are constant in space and time. Essentially, the composition of the water changing can be considered a result of intersections dur- 

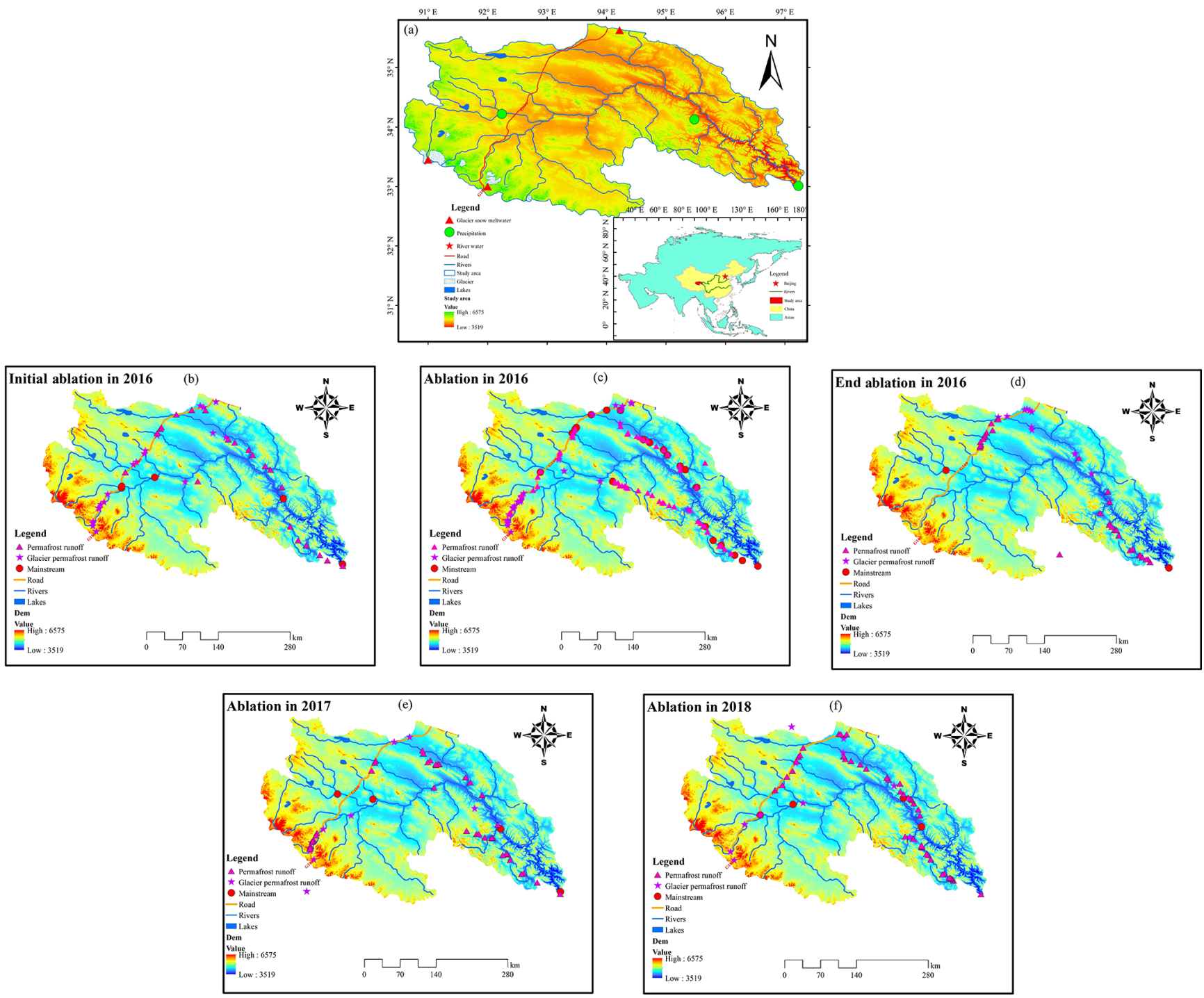

Figure 1. The map of the study area and the sampling point of river water in different ablation periods. (a shows the detailed location of the study area in China and Asia and the distribution of fixed points for precipitation, river water, and glacier and snow meltwater; $\mathbf{b}$ shows the distribution of sampling points in initial ablation in 2016; $\mathbf{c}$ shows the distribution of sampling points in ablation in 2016; d shows the distribution of sampling points in end ablation in 2016; e shows the distribution of sampling points in ablation in 2017; $\mathbf{f}$ shows the distribution of sampling points in ablation in 2018.)

ing its passage through each landscape zone. Tracers can be used to determine both sources and flow paths. The EMMA tracer approach has been a common method for analyzing potential water sources contributing to streamflow (Li et al., 2014a, 2016a). Here a three-end-member mass-balance mixing model is employed to calculate the contribution of up to three water sources in stream water, such as the following:

$X_{S}=F_{1} X_{1}+F_{2} X_{2}+F_{3} X_{3}$,

$Y_{S}=F_{1} Y_{1}+F_{2} Y_{2}+F_{3} Y_{3}$.

In Eq. (1), $X$ and $Y$ represent concentrations of two types of different tracers. In this study, $\delta^{18} \mathrm{O}$ and deuterium excess were chosen for comparison. The subscripts represent stream water sample, and 1, 2, and 3 represent water from the contribution of three respective source waters (end-members) to stream water. The fraction of each end-member is denoted by $F$. The solutions for $F_{1}, F_{2}$, and $F_{3}$ in regards to tracer concentrations in Eq. (1) can be given as

$$
\begin{aligned}
F_{1}= & {\left[\left(X_{3}-X_{S}\right) /\left(X_{3}-X_{2}\right)-\left(Y_{3}-Y_{S}\right) /\left(Y_{3}-Y_{2}\right)\right] / } \\
& {\left[\left(Y_{1}-Y_{3}\right) /\left(Y_{3}-Y_{2}\right)-\left(X_{1}-X_{3}\right) /\left(X_{3}-X_{2}\right)\right], } \\
F_{2}= & {\left[\left(X_{3}-X_{S}\right) /\left(X_{3}-X_{1}\right)-\left(Y_{3}-Y_{S}\right) /\left(Y_{3}-Y_{1}\right)\right] / } \\
& {\left[\left(Y_{2}-Y_{3}\right) /\left(Y_{3}-Y_{1}\right)-\left(X_{2}-X_{3}\right) /\left(X_{3}-X_{1}\right)\right], } \\
F_{3}= & 1-F_{1}-F_{2} .
\end{aligned}
$$


This method has been used in previous studies ( $\mathrm{Li}$ et al., 2014b, 2015, 2016b). This study also used this method to evaluate the contribution of possible sources to the river water.

\subsection{Uncertainty in hydrograph separation}

The uncertainty of tracer-based hydrograph separations can be calculated using the error propagation technique (Genereux, 1998; Klaus and McDonnell, 2013). This approach considers errors of all separation equation variables. Assuming that the contribution of a specific streamflow component to streamflow is a function of several variables $c 1$, $c 2, \ldots, c n$ and the uncertainty in each variable is independent of the uncertainty in the others, the uncertainty in the target variable (e.g., the contribution of a specific streamflow component) is estimated using the following equation (Genereux, 1998; Uhlenbrook and Hoeg, 2003):

$W f x$

$=\sqrt{\left(\frac{\partial z}{\partial c 1} W c 1\right)^{2}+\left(\frac{\partial z}{\partial c 2} W c 2\right)^{2}+\cdots+\left(\frac{\partial z}{\partial c n} W c n\right)^{2}}$,

where $W$ represents the uncertainty in the variable specified in the subscript. $f x$ is the contribution of a specific streamflow component $x$ to streamflow. The software package MATLAB is used to apply Eq. (3) to the different hydrograph separations in this study.

\section{Results}

\subsection{Temporal variation}

As shown in Fig. 2, stable isotope characteristics of $\delta^{18} \mathrm{O}$ and $d$-excess were different during different ablation for the different types of runoff. For the main stream, the $\delta^{18} \mathrm{O}$ in initial ablation was higher than end ablation, while the ablation period was the lowest. But $\delta^{18} \mathrm{O}$ in the ablation period showed a decreasing trend from 2016 to 2018 . With the same as $\delta^{18} \mathrm{O}, d$-excess in the different ablation periods was different (Fig. 2a, d). For the river in the glacier permafrost area, the order of $\delta^{18} \mathrm{O}$ for the different ablation periods and the ablation period from 2016 to 2018 was the same as the main stream order, but the values of $\delta^{18} \mathrm{O}$ were different for the main stream (Fig. 2b, e). For the river in the permafrost area, the variation in $\delta^{18} \mathrm{O}$ for the different ablation periods and ablation from 2016 to 2018 was the same as for the main stream and the river in the glacier permafrost area. However, the order of $d$-excess was different for the river in the permafrost area and the glacier permafrost area (Fig. 2c, f). In general, the $\delta^{18} \mathrm{O}$ in the main stream was more negative than that in the rivers in the glacier permafrost and permafrost areas. These results may be due to the fact that the highest runoff was for the main stream and that the effects of dilution result in lower isotope values. However, the $\delta^{18} \mathrm{O}$ in the river in the glacier permafrost area was more positive than that in the main stream and the river in the permafrost area. The effect of evaporation could explain these results, and the change in $d$-excess could also demonstrate the same.

\subsection{Spatial variation}

To analyze the spatial variation in $\delta^{18} \mathrm{O}$ based on the different ablation periods in 2016 and ablation from 2016 to 2018, spatial interpolation of all river water samples in the study area was performed using ArcGIS. The results are shown in Fig. 3. The $\delta^{18} \mathrm{O}$ value in the north-central region of the study area was more positive than those in other regions. In the southeastern part of the study area, especially the QML, $\mathrm{ZMD}$, and Tanggula Mountains, the values were more negative during the initial ablation period. The area of positive ablation during the ablation period, which was concentrated mainly in the northeast part of the study area, was larger than that during the initial ablation. The other regions, except some areas in the southwest, turned positive. The area of positive ablation was largest during the final ablation period in 2016; all areas, except some in the eastern region of the study area, were positive (Fig. 3). The area of positive ablation in the central and northern regions began to expand in 2017 compared to the area of ablation in 2016. Furthermore, the area of negative ablation appears mainly in the southeastern and southwestern portions of the study area. However, the positive ablation area was also concentrated in the central and northern regions in 2018, and it was greater than it was in 2016 and 2017. Meanwhile, the negative ablation area appeared mainly in the southeastern and southwestern portions of the study area, but it was smaller than in 2016 and 2017. These results may be related to evaporation, possible recharge sources, or meteorological factors. These results were comprehensive and influenced by meteorological factors and the type and proportion of recharge sources. The evaporation effect was strong in the central and northern regions, which were also the major glacier and permafrost regions. The southeastern region was the downstream area where all runoff converged; thus, the dilution effect led to a more negative $\delta^{18} \mathrm{O}$ here. Moreover, the Tanggula Mountains, with altitudes higher than those in other regions, were located southwest of the study area; thus, evaporation had a low influence on this region, and the oxygen stable isotopes were more negative.

Just as with the spatial distribution of $\delta^{18} \mathrm{O}$, there was a significant spatial distribution of $d$-excess in the study area (Fig. 4). Compared to the spatial distribution of $\delta^{18} \mathrm{O}$, the $d$-excess in the central and northern regions was lower than that in the other regions. However, $d$-excess was higher in the latter, especially in the southwestern regions and in the southeastern regions during the initial ablation period. The lower area began to expand during the ablation period in 2016, while the central and northeastern regions and the Tanggula Mountains were greater. Meanwhile, the negative ablation 

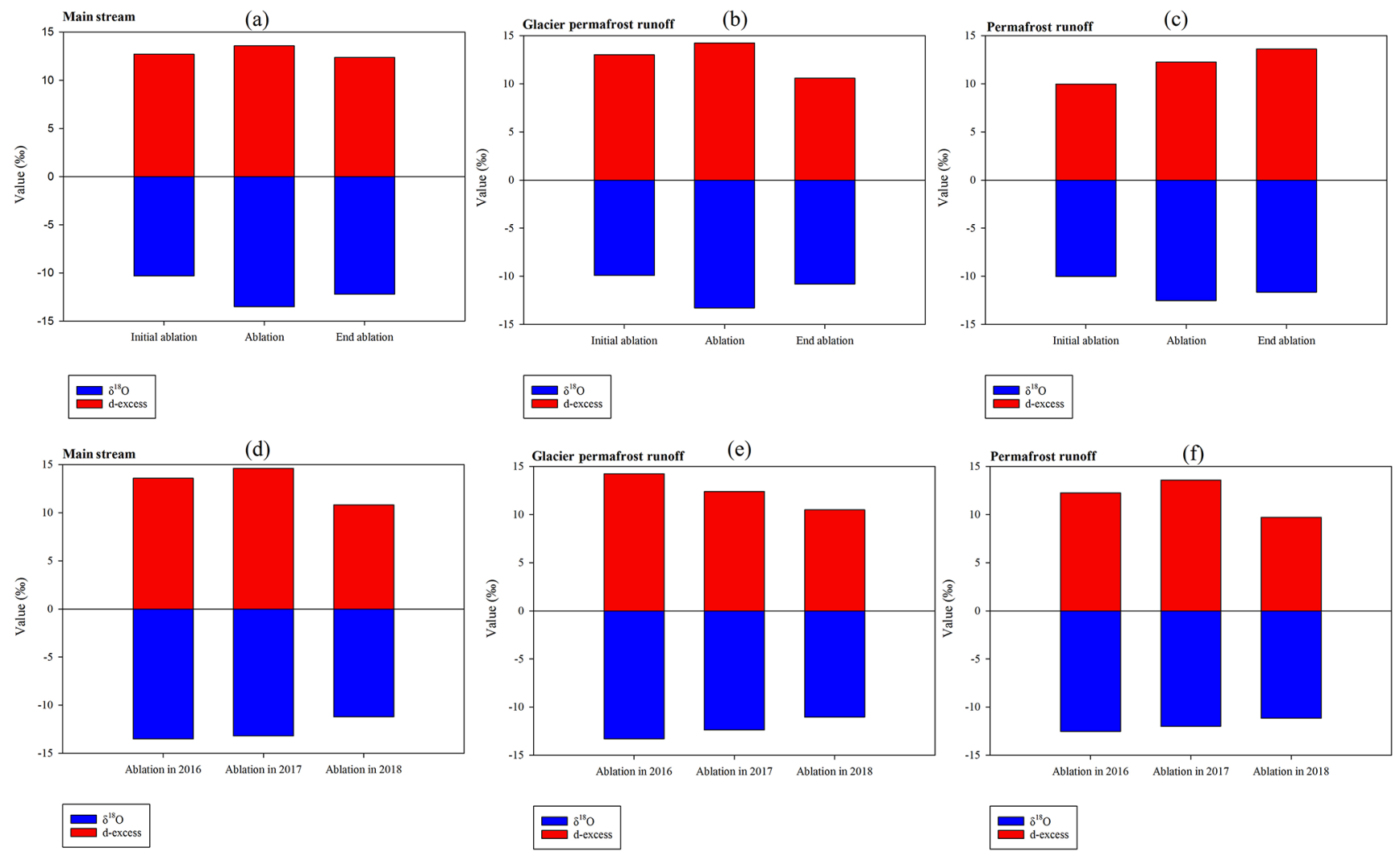

Figure 2. Temporal variation in $\delta^{18} \mathrm{O}$ and $d$-excess during the sampling period in the study area. (This figure mainly shows the temporal variation in $\delta^{18} \mathrm{O}$ and $d$-excess for different types of runoff based on different ablation in 2016 and strong ablation from 2016 to 2018 ; a-c shows the change of $\delta^{18} \mathrm{O}$ and $d$-excess in different ablation periods for the main stream, glacier and snow runoff, and river in permafrost area; $\mathbf{d}-\mathbf{f}$ shows the change of $\delta^{18} \mathrm{O}$ and $d$-excess in the ablation period from 2016 to 2018 for the main stream, glacier and snow runoff, and river in permafrost area.)

area continued to expand during the end ablation period; ablation was greater only in the southeastern part of the study area. However, all regions except for areas in the eastern region where the ablation was low during the ablation period in 2017 exhibited high ablation, especially the Tanggula Mountains. Moreover, the lower-ablation regions appeared mainly in the central and southeastern regions of the study area; values were higher in the other regions, especially in the Tanggula Mountains and the northeast. The spatial distribution of $d$-excess also confirmed the spatial distribution of the oxygen stable isotope because evaporation resulted in the enrichment of isotopes and led to a reduction in $d$-excess.

In general, the influence of evaporation on the isotope and $d$-excess was only manifested in some places, such as the central and northern parts of the study area, in the initial ablation and the ablation periods. However, the influence of evaporation on the isotope and $d$-excess was manifested in most places, except the southeast of the study area. Meanwhile, these results also indicated that there may be a hysteresis for the influence of meteorological factors on isotopes and $d$-excess. On the one hand, river water was the result of the final convergence of various recharge sources that include precipitation, supra-permafrost water, and glacier and snow meltwater. On the other hand, meteorological factors directly affected the main recharge sources of river water.

As shown in Fig. 5, there was a significant difference in the variation in $\delta^{18} \mathrm{O}$ and $d$-excess with altitude for the main stream, the river in the glacier permafrost area, and the river in the permafrost area of the study area. For the main stream, the oxygen stable isotope showed a decreasing trend, with increases in altitude, during the ablation periods in 2016 and 2018. In other words, the altitude effect only appeared in the ablation periods during these 2 years and had values of $-0.16 \%$ every $100 \mathrm{~m}(p<0.05)$ and $-0.14 \%$ every $100 \mathrm{~m}(p<0.05)$. However, $\delta^{18} \mathrm{O}$ showed an increasing trend with an increase in altitude during the initial and end ablation periods in 2016 and the ablation period in 2017. The anti-altitude effects of the initial and end ablation periods in 2016, and ablation period in 2017 , were $0.11 \%$ every $100 \mathrm{~m}(p<0.05), 0.13 \%$ every $100 \mathrm{~m}(p<0.01)$, and $0.04 \%$ every $100 \mathrm{~m}(p<0.05)$, respectively. For the phenomenon of anti-altitude effect, the following reasons can explain this phenomenon: on the one hand, in the source area of the river, the stable isotope concentration of precip- 

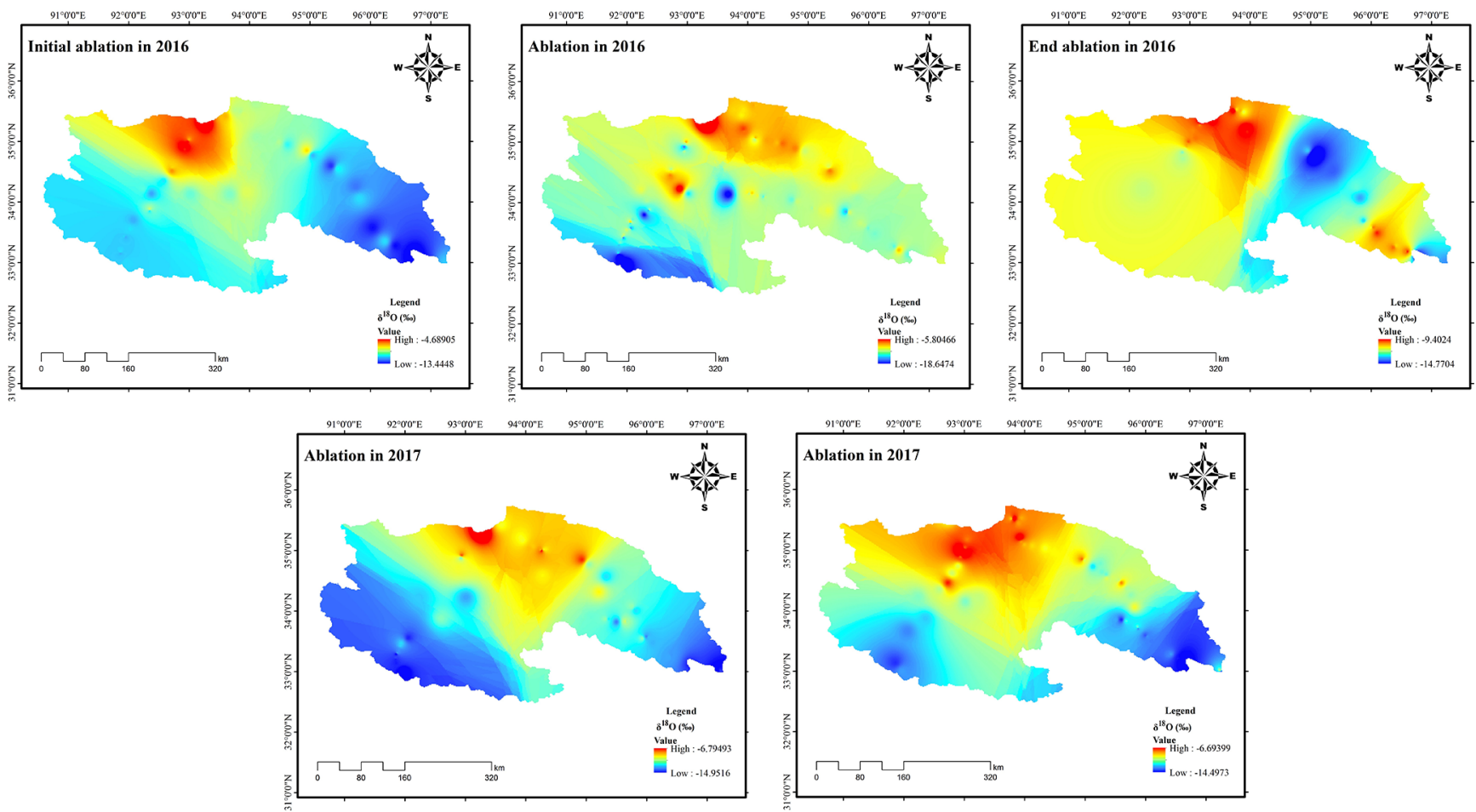

Figure 3. Spatial variation in $\delta^{18} \mathrm{O}$ based on different ablation in 2016 and ablation from 2016 to 2018 .
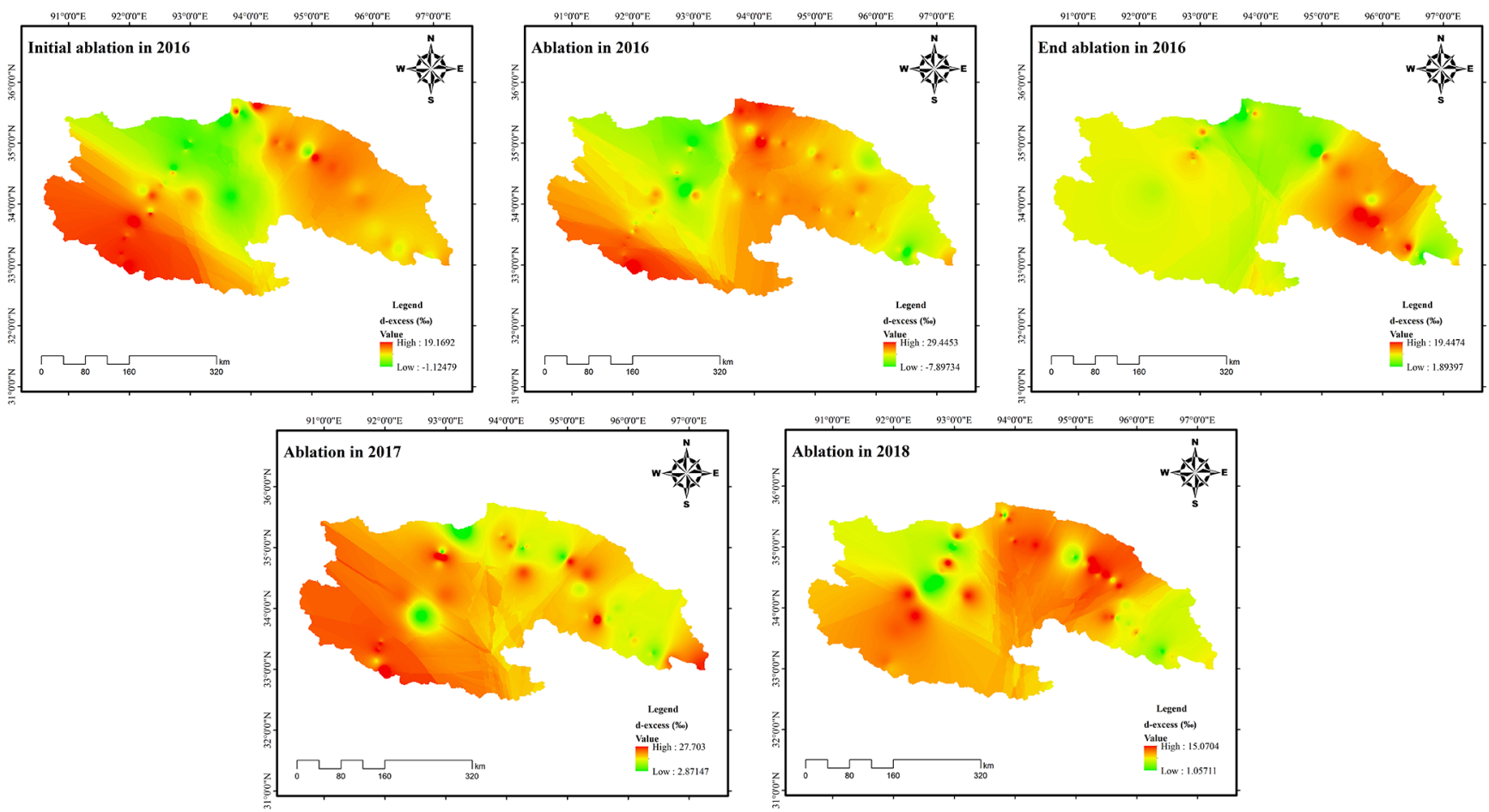

Figure 4. Spatial variation in $d$-excess based on different ablation in 2016 and ablation from 2016 to 2018 . 
itation and glacier snow meltwater is relatively low and the value of groundwater in the permafrost active layer is relatively positive due to the influence of soil evaporation. On the other hand, the greater the inflow of precipitation, the greater the contribution of precipitation. So there is an obvious diluting effect of biotin, which makes the concentration more negative. $d$-excess showed a decreasing trend during the initial and end ablation periods in 2016 and a significant increasing trend in the ablation period from 2016 to 2018 . For the river in the glacier permafrost area, $\delta^{18} \mathrm{O}$ showed a decreasing trend with an increase in altitude during the ablation periods in 2016 and 2018, but the ablation in 2018 was not significant. The altitude effect was $-0.66 \%$ every $100 \mathrm{~m}(p<0.05)$ and $-0.15 \%$ every $100 \mathrm{~m}(p>0.05)$, respectively, during the former two periods. Moreover, a significant anti-altitude effect of $0.47 \%$ every $100 \mathrm{~m}(p<0.05)$, $0.67 \%$ overy $100 \mathrm{~m}(p<0.05)$, and $0.97 \%$ every $100 \mathrm{~m}$ $(p<0.05)$, appeared in the initial and end ablation periods in 2016 and the ablation period in 2017, respectively. Just as with the main stream, $d$-excess showed a decreasing trend in the initial and end ablation periods in 2016 and an increasing trend in the ablation from 2016 to 2018 . For the river in the permafrost area, $\delta^{18} \mathrm{O}$ showed a decreasing trend with an increase in altitude in the initial ablation period and ablation period in 2016, with an altitude effect of $-0.38 \%$ every $100 \mathrm{~m}(p<0.05)$ and $-0.12 \%$ every $100 \mathrm{~m}(p>0.05)$, respectively. However, $\delta^{18} \mathrm{O}$ showed an increasing trend with increase in altitude in the end ablation period in 2016 and the ablation periods in 2017 and 2018, with an anti-altitude effect of $0.21 \%$ every $100 \mathrm{~m}(p<0.05), 0.01 \%$ overy $100 \mathrm{~m}$ $(p>0.05)$, and $0.68 \%$ o every $100 \mathrm{~m}(p<0.05)$, respectively. $d$-excess showed an increasing trend with increase in altitude in the initial and end ablation periods in 2016 and ablation periods in 2016 and 2017. However, $d$-excess also showed a decreasing trend with increase in altitude in the ablation period in 2018.

In summary, the altitude effect mainly appeared during ablation, whether it was in the main stream, the river in the glacier permafrost area, or the river in the permafrost area. The altitude effects were higher for the river in the glacier permafrost area than for the main stream or the river in the permafrost area during the ablation period in 2016. Meanwhile, the anti-altitude effect of the river in the glacier permafrost area was higher than that of the other areas. The $\delta^{18} \mathrm{O}$ during the initial and end ablation periods in 2016 showed a significant anti-altitude effect for the main stream and the river in the glacier permafrost area; a significant altitude effect appeared during the initial ablation period for the river in the permafrost area. These results may be due to the comprehensive influence of possible recharge sources and different recharge proportions caused by the influence of meteorological factors. This kind of comprehensive influence is mainly due to the significant seasonality of climate factors in the cold regions, which directly determines the types and contribution proportion of possible recharge sources. Therefore, this result can not be said to be caused by any one factor, but can only be explained by the comprehensive influence of possible recharge sources and different recharge proportions caused by the influence of meteorological factors.

\subsection{Evaporation line}

The variations in the location of the evaporation line for river water during the different ablation periods in 2016 and the ablation periods from 2016 to 2018 are shown in Fig. 6. The slope and intercept of the location evaporation line (LEL) for river water showed an increasing trend from the initial to end ablation periods in 2016. The LEL in the initial ablation period was $\delta \mathrm{D}=6.59 \delta^{18} \mathrm{O}-3.60(p<0.01)$, and it was $\delta \mathrm{D}=6.88 \delta^{18} \mathrm{O}-1.37(p<0.01)$ during the ablation period. The LEL during the end ablation period was $\delta \mathrm{D}=7.39 \delta^{18} \mathrm{O}+5.88(p<0.01)$. These results indicate that the effect of evaporation on the stable isotopes in river water gradually weakened from the initial ablation to the end ablation periods. The slope and intercept of the LEL of river water during the ablation period in 2017 were lower than those in 2016. The LEL during the ablation period in 2017 was $\delta \mathrm{D}=6.59 \delta^{18} \mathrm{O}-3.63(p<0.01)$. However, regardless of whether the slope or the intercept of LEL of river water in 2018 was higher than that in 2016 and 2017, the LEL was $\delta \mathrm{D}=7.63 \delta^{18} \mathrm{O}+5.82(p<0.01)$. This phenomenon showed that the influence of evaporation on stable isotope levels was greatest during the ablation period in 2017 , followed by that in 2016. In general, the lower slope and intercept indicate that the water body was affected by evaporation or nonequilibrium dynamic fractionation. This conclusion could also explain the results of this study.

\subsection{Recharge sources}

The distribution of $\delta \mathrm{D}$ and $\delta^{18} \mathrm{O}$ for river water among other water bodies is shown in Fig. 7 during the different ablation periods in 2016 and ablation from 2016 to 2018 . The results of the distribution of $\delta \mathrm{D}$ and $\delta^{18} \mathrm{O}$ of river water indicate the possible recharge sources of river water. However, the $\delta \mathrm{D}$ and $\delta^{18} \mathrm{O}$ of river water, supra-permafrost water, glacier snow meltwater, and precipitation exhibited little change during the initial ablation in 2016 (Fig. 7a, b). This phenomenon suggests that precipitation may be the major recharge sources for river water during the initial ablation. A plot of $\delta \mathrm{D}$ versus $\delta^{18} \mathrm{O}$ for river and supra-permafrost water, glacier snow meltwater, and precipitation is shown in Fig. 7c. The $\delta \mathrm{D}$ and $\delta^{18} \mathrm{O}$ values of glacier and snow meltwater from above the local meteorological water line (LMWL) are the most negative compared to other water bodies. The stable isotope of supra-permafrost water was relatively more positive, located below the LMWL, confirming the influence of strong evaporation. The stable isotope of river water was close to the LMWL, and its concentration value was between precipitation, glacier and snow meltwater, and supra-permafrost wa- 

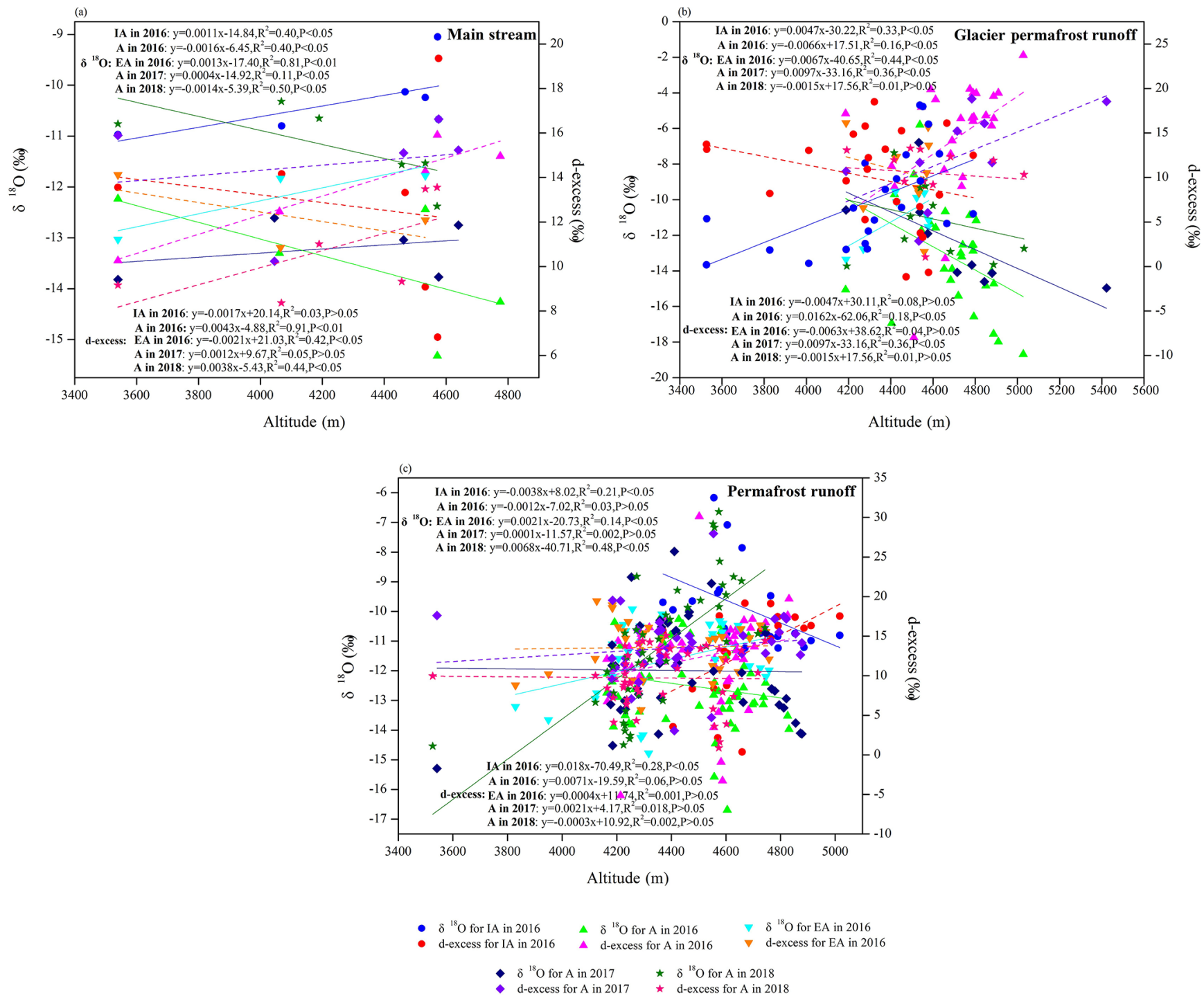

Figure 5. The variation in $\delta^{18} \mathrm{O}$ and $d$-excess with the altitude change in study area. (a shows the variation in $\delta^{18} \mathrm{O}$ and $d$-excess with the altitude change for main stream; $\mathbf{b}$ shows the variation in $\delta^{18} \mathrm{O}$ and $d$-excess with the altitude change for river in glacier permafrost area; c shows the variation in $\delta^{18} \mathrm{O}$ and $d$-excess with the altitude change for river in permafrost area; IA in 2016 represents initial ablation in 2016; A in 2016 represents ablation in 2016; EA in 2016 represents end ablation in 2016; A in 2017 represents ablation in 2017; A in 2018 represents ablation in 2018.)

ter, reflecting that river water was recharged and affected by multi-source water in the study area. Moreover, the distribution of river water, glacier and snow meltwater, and suprapermafrost water also indicated that there was a hydraulic relationship between the source and target in the different ablation periods in 2016 and ablation from 2016 to 2018.

The mixed segmentation model of the end-member is used to determine the contribution proportions of different water sources to the target water. Owing to the two stable isotope concentrations in different water bodies having significant spatial and temporal differences, it can effectively distinguish different water bodies and their mixing relationships. The $d$ excess and $\delta^{18} \mathrm{O}$ are used as tracers of the mixed segmen- tation model of the end-elements. As shown in Fig. 8, according to the locations of the different types of water and the distance from other water bodies, which reflected the mixed recharge of three water bodies, supra-permafrost water was the first end element, precipitation was the second end element, and glacier and snow meltwater was the third end element. However, the different runoffs likely have different recharge sources and different recharge proportions. The glacier permafrost area river comprised glacier and snow meltwater more in the ablation period than in other periods. Compared with the permafrost area river and the glacier permafrost area river, the main stream was governed by the supra-permafrost water in the initial ablation period while 

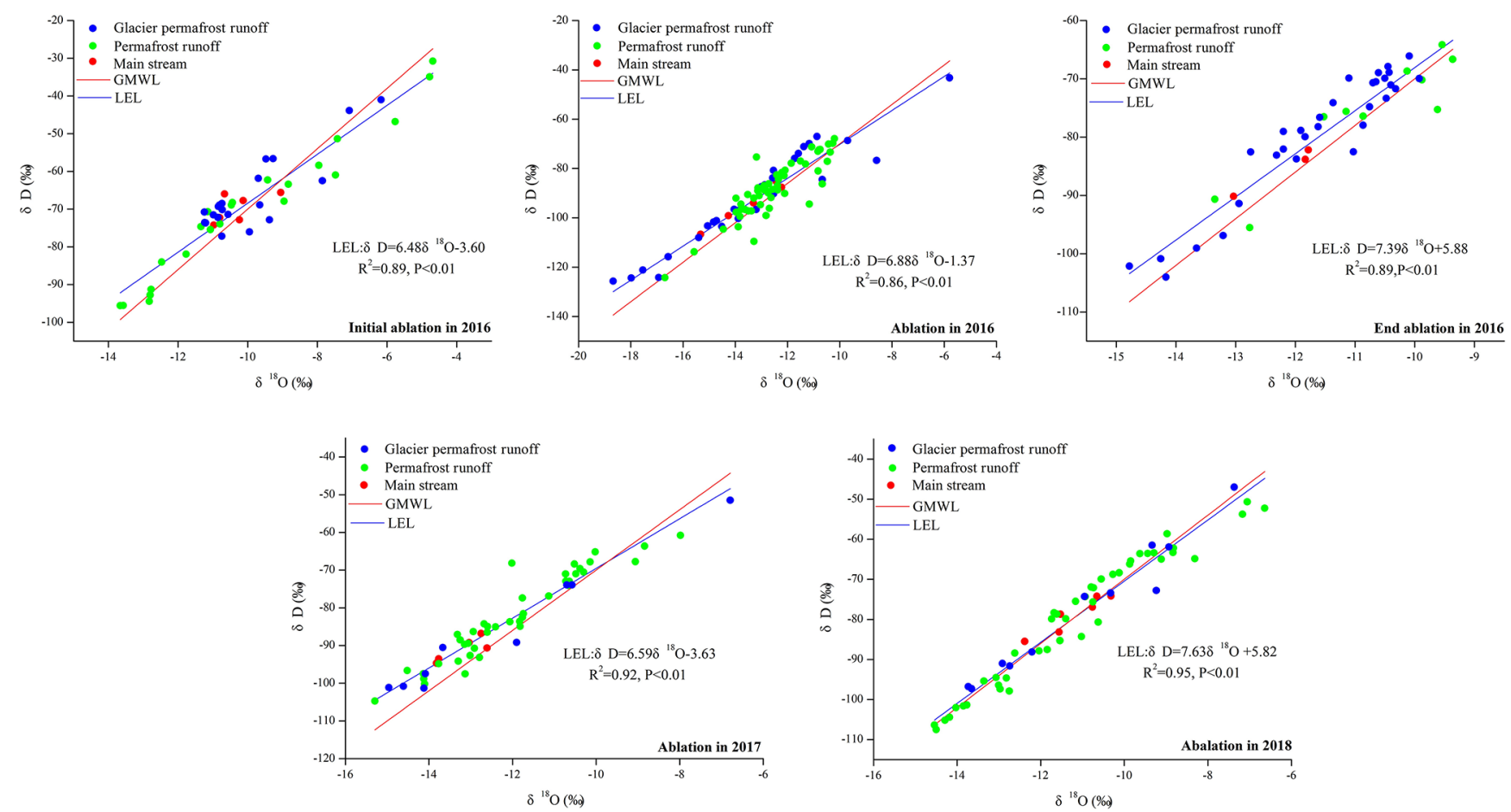

Figure 6. The variation in location evaporation line (LEL) of river water based on different ablation in 2016 and ablation from 2016 to 2018.

containing nearly equal proportions of supra-permafrost water and precipitation in the end ablation period. However, the main stream received significant contributions from all three end-members in the ablation period from 2016 to 2018 and particularly in 2017.

The recharge proportions of precipitation, suprapermafrost water, and glacier and snow meltwater at different altitudes are depicted in Fig. 9, from the mixed segmentation model of the three end-members during the ablation periods mentioned above. The recharge proportions of the three end-members in the ablation periods were significantly different. This may be due to the different effects of the runoff recharge sources in different ablation periods, as well as the significant differences in recharge and drainage relationships in the different ablation periods. The recharge proportions of precipitation in the initial ablation in 2016, ablation in 2016, end ablation in 2016, ablation in 2017, and ablation in 2018 , obtained by calculating the average contribution proportion from each altitude, were $28.71 \%$, $44.41 \%, 44.60 \%, 42.53 \%$, and $51.03 \%$, respectively. Meanwhile, the recharge proportions of supra-permafrost water in the initial ablation in 2016, ablation in 2016, end ablation in 2016, ablation in 2017, and ablation in 2018 were $55.38 \%, 36.51 \%, 40.21 \%, 37.56 \%$, and $28.87 \%$, respectively. The recharge proportions of glacier and snow meltwater in the initial ablation in 2016, ablation in 2016, end ablation in 2016, ablation in 2017, and ablation in 2018 were $15.91 \%, 19.08 \%, 15.19 \%, 19.90 \%$, and $20.09 \%$, respectively. The recharge proportion of precipitation decreased with increase in altitude in the initial ablation, while the proportion of supra-permafrost water and glacier and snow meltwater exhibited an increasing trend with increase in altitude. However, the recharge proportion of the supra-permafrost water was higher than that of precipitation or glacier and snow meltwater and also showed a decreasing trend from low to high altitude in the end ablation in 2016. The proportion of glacier and snow meltwater increased with increase in altitude, but the recharge proportion of suprapermafrost water was stable with the change in altitude in the end ablation in 2016. The trend of precipitation and glacier and snow meltwater for the ablation was the same as that for the initial and end ablation. However, the recharge proportion of precipitation was higher than the proportion of supra-permafrost water and glacier and snow meltwater in the ablation period. Meanwhile, the recharge proportion of glacier and snow meltwater in ablation was higher than that in the initial and end ablation period. In general, the recharge of supra-permafrost water to runoff was stable, whether in the different ablation periods in 2016 or the ablation from 2016 to 2018. However, the proportion of supra-permafrost water was relatively low, mainly due to the larger runoff during the ablation period.

Using the approach shown in Eq. (3), the uncertainty originating from the variation in the tracers of components and measurement methods could be calculated separately (Uhlenbrook and Hoeg, 2003; Pu et al., 2013). According to the 

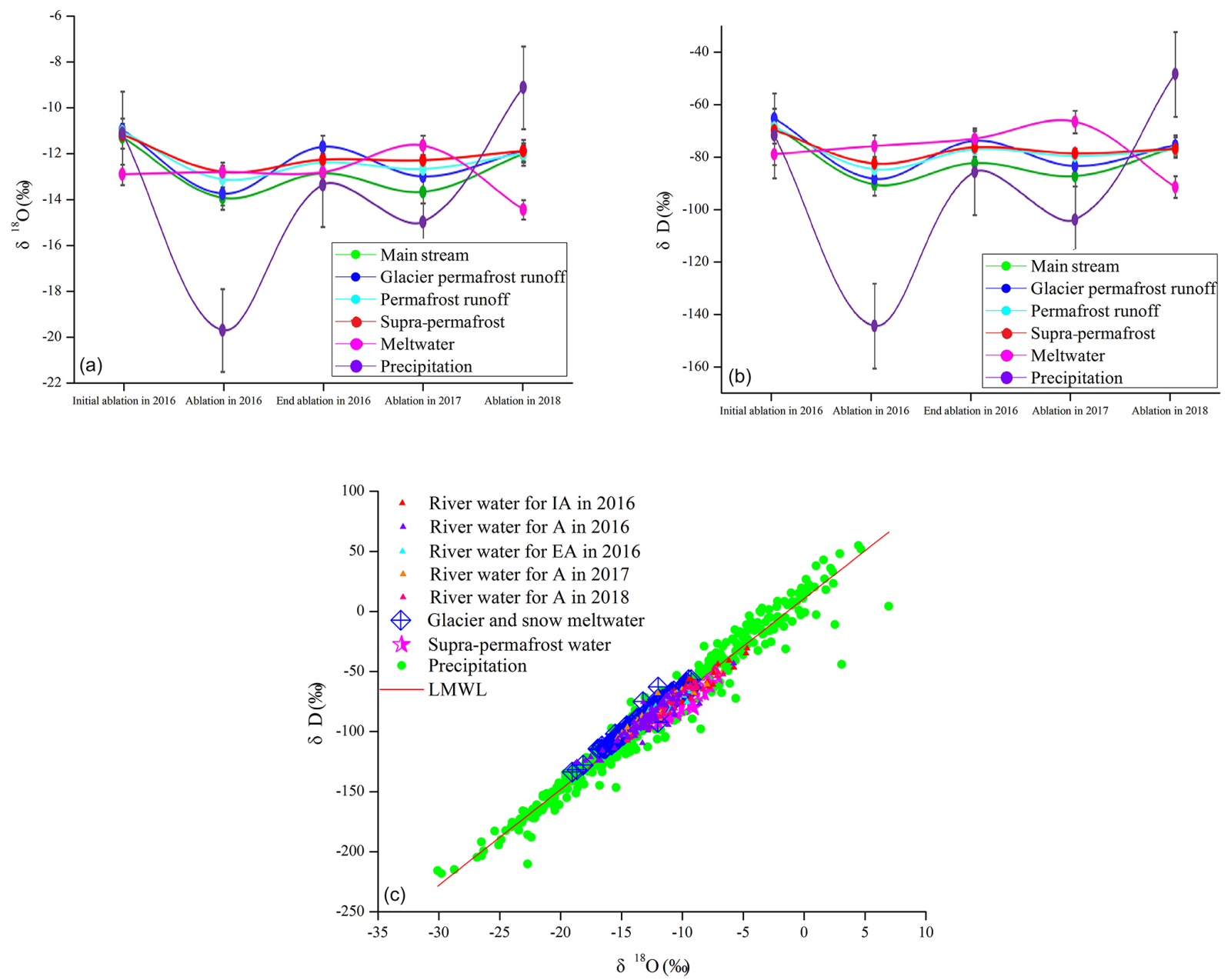

Figure 7. The distribution of $\delta \mathrm{D}$ and $\delta^{18} \mathrm{O}$ for river water among other water bodies in study area. (a shows the plot of $\delta^{18} \mathrm{O}$ for river water in different type, supra-permafrost water, glacier snow meltwater, and precipitation; $\mathbf{b}$ shows the plot of $\delta \mathrm{D}$ for river water in different type, supra-permafrost water, glacier snow meltwater, and precipitation; $\mathbf{c}$ shows the plot of $\delta \mathrm{D}$ versus $\delta^{18} \mathrm{O}$ for river water, supra-permafrost water, glacier snow meltwater, and precipitation.)

calculations made using Eq. (3), the uncertainty was estimated to be 0.07 for the three-component mixing model in the study region. The uncertainty terms for supra-permafrost water accounted for more than $50.0 \%$ of the total uncertainty, indicating that the $\delta^{18} \mathrm{O}$ and $\delta \mathrm{D}$ variations in suprapermafrost water accounted for the majority of the uncertainty. Although there is some uncertainty for hydrograph separation, isotope-based hydrograph separations are still valuable tools for evaluating the contribution of meltwater to water resources, and they are particularly helpful for improving our understanding of hydrological processes in cold regions, where there is a lack of observational data.

\section{Discussions}

\subsection{Meteorological factors}

To further explain the reason for the variation in temporal and spatial characteristics of stable isotopes and LEL, this study includes the analysis of the monthly change in precipitation, temperature, relative humidity, and evaporation during the sampling period (from January 2016 to December 2018). The results are shown in Fig. 10. The average of the precipitation was $371.9 \mathrm{~mm}$ during the sampling period, and the precipitation in the ablation period accounted for $78.87 \%$. The averages of the temperature, relative humidity, and evaporation during the sampling period were $-1.42^{\circ} \mathrm{C}, 52.20 \%$, and $4.14 \mathrm{~mm}$, respectively. However, the averages of the temperature, relative humidity, and evaporation during the ablation period were $8.04{ }^{\circ} \mathrm{C}, 66.47 \%$, and $5.57 \mathrm{~mm}$, respectively. 

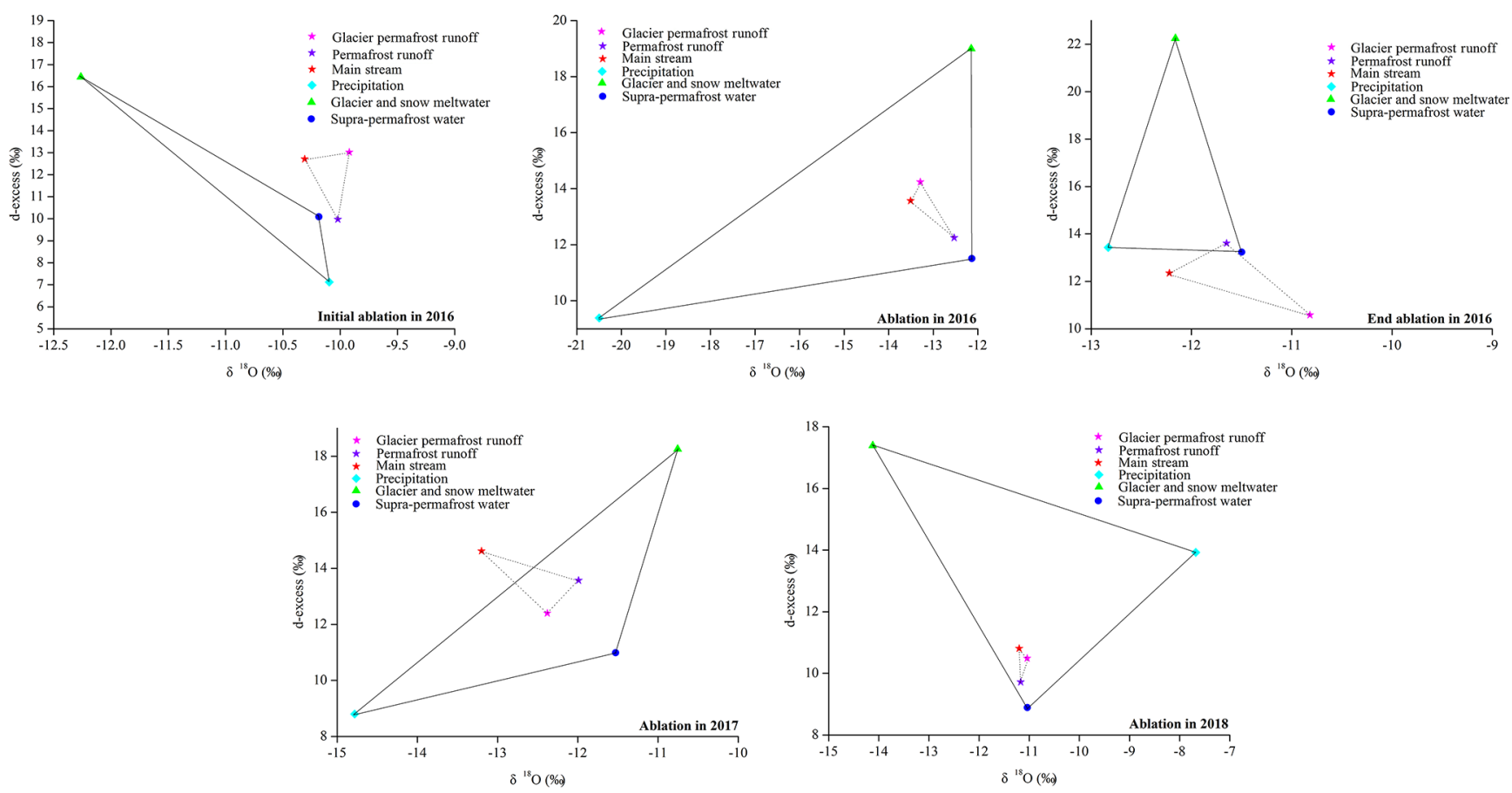

Figure 8. Three-end-element diagram using the mean values of $\delta^{18} \mathrm{O}$ and $d$-excess for river water in different ablation in 2016 and ablation from 2016 to 2018.
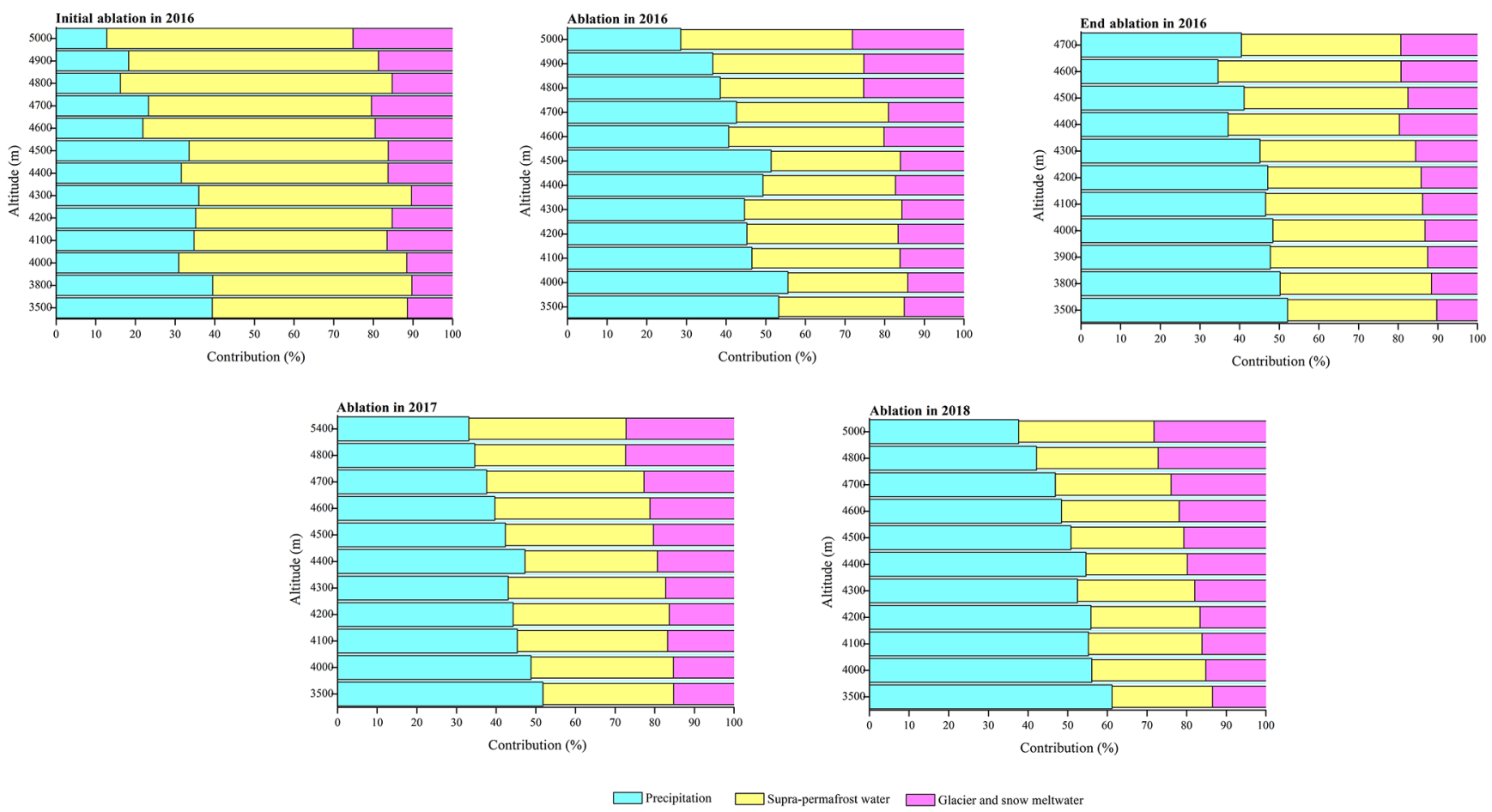

Figure 9. Recharge proportion from possible sources to river water at different altitudes during different ablation in 2016 and ablation from 2016 to 2018 . 


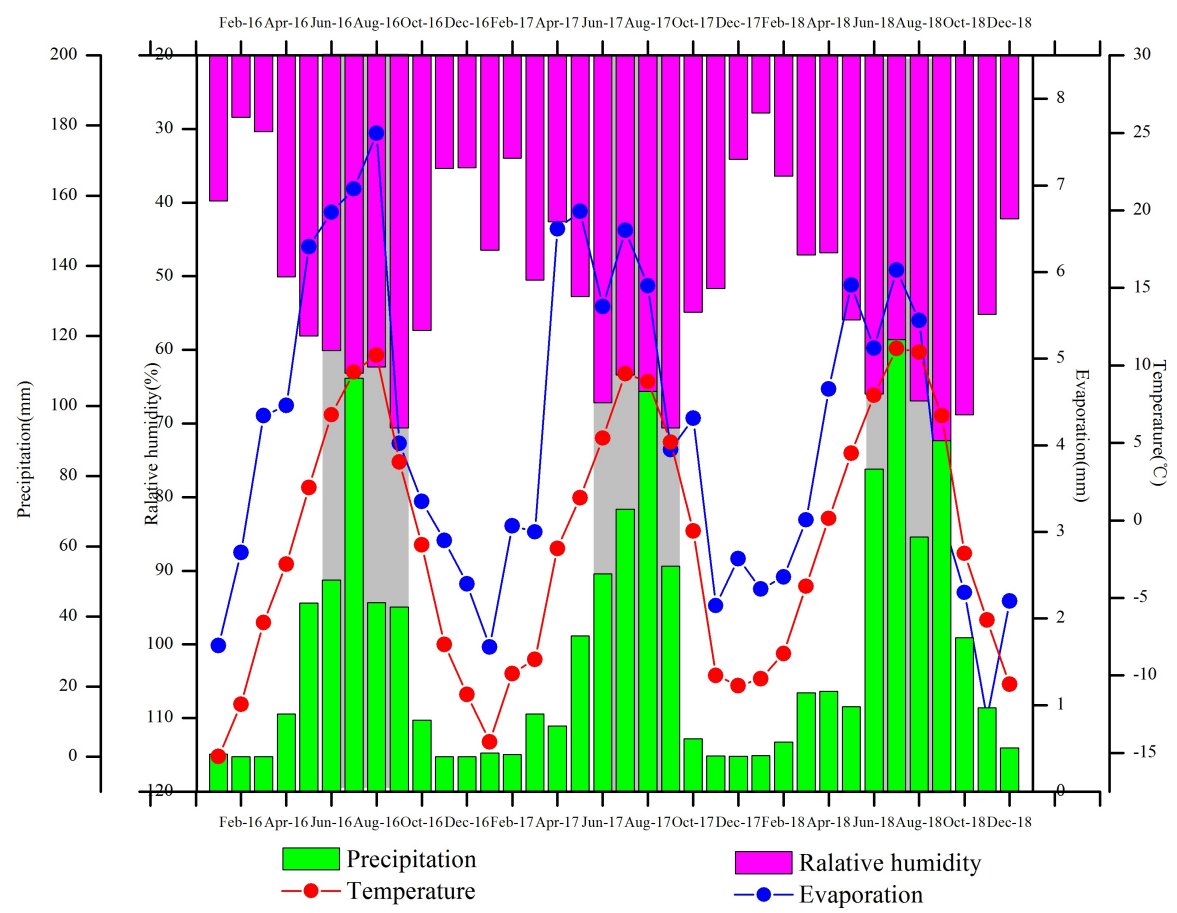

Figure 10. Variation in meteorological factors during the sampling period (shadow represents the ablation period).

More importantly, the precipitation during the initial, total, and end ablation periods in 2016 and the ablation periods in 2017 and 2018, were 50.40, 107.90, 42.90, 70.60, and $119.00 \mathrm{~mm}$, respectively. For precipitation, the isotope levels tend to decrease with the increase in rainfall. Precipitation is also the major source of water for all water bodies (Maurya et al., 2011; Pu et al., 2013; Li et al., 2014b; 2015; 2016a; 2018; Pan et al., 2017), and, in general, more precipitation resulted in a greater dilution effect. A more negative $\delta^{18} \mathrm{O}$ appeared in the ablation period in 2016 in all three study areas given the change in $\delta^{18} \mathrm{O}$ (Fig. 2). This result showed that dilution not only plays an important role in the precipitation effect, but it also affects river water. However, the dilution effect was also significant when precipitation was the major recharge source for river water (Abongwa and Atekwana, 2018; Li et al., 2015).

Temperature for the initial, total, and end ablation periods in 2016 and the ablation periods in 2017 and 2018, were 6.82, 9.58, 3.77, 9.47, and $11.09^{\circ} \mathrm{C}$, respectively. For atmospheric precipitation, the lower the temperature was, the higher the condensation degree of water vapor exhibited and the lower the isotope content in precipitation. Therefore, there is a positive correlation between the stable isotope and temperature in precipitation ( $\mathrm{Li}$ et al., 2016a). However, the influence of temperature on the stable isotope of river water was not significant from the variation in river water isotope during the different ablation periods. However, the variation trend of the stable isotope of river water in the ablation period from 2016 to 2018 was similar to that for the change in temperature. Meanwhile, the variation trend of $d$-excess can also be confirmed by this analysis (Fig. 2).

Relative humidity in the initial ablation, ablation, and end ablation periods in 2016 and the ablation periods in 2017 and 2018 was $60.07 \%, 63.16 \%, 70.57 \%, 63.39 \%$, and $63.48 \%$, respectively. When the relative humidity is low, the dynamic fractionation increases and the slope decreases, and vice versa. The variation trend of the slope of the LEL for the different ablation periods in 2016 was the same as that for the change in relative humidity (Fig. 6). Meanwhile, the intercept of the LEL for the different ablation periods in 2016 also showed the same trend.

Evaporation in the initial ablation, ablation, and end ablation periods in 2016 and ablation periods in 2017 and 2018 was $6.69,6.96,4.02,6.48$, and $6.02 \mathrm{~mm}$, respectively. The stable isotopes of hydrogen and oxygen in river water are comprehensively affected by the evaporation process, runoff change, precipitation recharge, glacier and snow meltwater recharge, and supra-permafrost water in cold regions. During the process of evaporation, lighter water isotopes are separated preferentially from the surface of water while heavier isotopes are enriched in the remaining water body. Evaporation enriches the oxygen and hydrogen stable isotopes and reduces excess deuterium ( $\mathrm{Li}$ et al., 2015, 2018). The trend in the oxygen isotope in the ablation periods from 2016 to 2018 
was the same as that for the change in evaporation (Fig. 2). Meanwhile, the spatial distribution of $\delta^{18} \mathrm{O}$ and $d$-excess also responded to this change (Figs. 3, 4).

To further analyze the influence of meteorological factors on the stable isotope, the correlation between meteorological factors and the monthly value of $\delta^{18} \mathrm{O}$ and $d$-excess, which showed continuous observations at two fixed-point stations, was analyzed (Table 1), and the results are shown in Table 1 . There was a significant negative correlation between precipitation and $\delta^{18} \mathrm{O}$ at the 0.01 level (two-tailed), while a significant positive correlation between precipitation and $d$-excess was also present. More interestingly, just as with precipitation, a significant negative correlation appeared between $\delta^{18} \mathrm{O}$ and temperature, relative humidity, and evaporation, with coefficients of $-0.671,-0.555$, and -0.636 , respectively. Meanwhile, a significant positive correlation occurred between $d$-excess and temperature, relative humidity, and evaporation, with coefficients of $0.602,0.524$, and 0.533 , respectively. These results indicated that the direct influence of meteorological factors on stable isotopes of river water was significant and definite.

Hydrogen and oxygen isotope compositions in river water are the result of the combined effects of the isotopes present in precipitation, glacier and snow meltwater, and supra-permafrost water as well as evaporative fractionation (Li et al., 2015). The main influential hydrometeorological factors include precipitation, temperature, relative humidity, and evaporation. On the whole, river water isotopes were not influenced by a single factor; instead, they were based on the comprehensive influence of many factors in the cold regions. The influence of meteorological factors on different types of river water (main stream, rivers in glacier permafrost areas, and rivers in permafrost areas) showed that apart from their direct influences, each factor indirectly affected the river water recharge source. This indirect influence was mainly felt on precipitation, glacier, snow, and permafrost.

\subsection{Hydrological processes}

To systematically quantify the main recharge sources of different types of runoff in the alpine regions, the possible sources and recharge proportions of runoff of different types in different ablation periods were deeply analyzed by using the mixed segmentation model of the three end-members in this study. The conceptual model map of the recharge form and proportion of the river water in the different ablation periods is shown in Fig. 11.

For the river in the glacier permafrost area, there was a significant difference in the recharge proportion in the runoff area, in which there were several glaciers and permafrost in the basin, and other areas during the various ablation periods. The proportion of recharge from precipitation during the initial, total, and end ablations in 2016, the ablation in 2017, and the ablation in 2018 was $27.69 \%, 33.71 \%$, $32.38 \%, 33.21 \%$, and $41.48 \%$, respectively. However, the proportions of supra-permafrost water in the initial, total, and end ablations in 2016, the ablation in 2017, and the ablation in 2018 were $54.68 \%, 35.96 \%, 46.38 \%, 37.39 \%$, and $36.63 \%$, respectively. The proportions of glacier and snow meltwater in the initial, total, and end ablations in 2016, the ablation in 2017, and the ablation in 2018 were $17.63 \%$, $30.33 \%, 21.24 \%, 29.39 \%$, and $22.19 \%$, respectively. These results show that supra-permafrost water was the important recharge source for runoff during the initial and end ablation periods. The proportion of supra-permafrost water was $50.53 \%$ during the initial and end ablation periods. It was also the next highest source of runoff recharge, next to precipitation, during the ablation from 2016 to 2018; the proportions were $36.13 \%$ and $36.66 \%$, respectively. The recharge proportions for glacier and snow meltwater were higher during the ablation period than in the initial and end ablation periods, at $19.44 \%$ and $27.30 \%$, respectively.

For permafrost area river, the runoff area only with permafrost and no glacier in the basin, there was also an obvious difference for the recharge proportion in different ablation periods. Compared with the glacier permafrost area river the recharge proportion of supra-permafrost water was higher for permafrost area river than that for the glacier permafrost area river $(42.21 \%)$. The recharge proportion of supra-permafrost water was $69.54 \%$. With the same as the glacier permafrost area river, the supra-permafrost water was the important recharge source to runoff in the initial and end ablation periods, and the proportion was $80.97 \%$ in the initial and end ablation periods. Meanwhile, the proportion of supra-permafrost water was $61.92 \%$ in the ablation period. The proportion was higher than that for precipitation $(24.13 \%)$ in the ablation period. In general, the supra-permafrost water was the major recharge source for the permafrost area river in the different ablation periods in the study area. Meanwhile, the glacier and snow meltwater had little contribution to the permafrost area river in the initial and end ablation periods.

For the main stream, the recharge proportions for precipitation during the initial, total, and end ablations in 2016, the ablation in 2017, and the ablation in 2018 were $28.67 \%$, $48.35 \%, 43.18 \%, 46.97 \%$, and $41.33 \%$, respectively. The proportion was $35.93 \%$ in the initial and end ablation periods and $45.55 \%$ in the ablation period. However, the proportions of supra-permafrost water during the initial, total, and end ablation in 2016, the ablation in 2017, and the ablation in 2018 were $52.37 \%, 33.52 \%, 42.61 \%, 39.68 \%$, and $38.21 \%$, respectively. The proportion was $47.49 \%$ during the initial and end ablation periods and $36.47 \%$ during the ablation period. These results indicate that, for the study area, the supra-permafrost water was the major recharge source for the main stream in the first two of these ablation periods while precipitation was the major recharge source for the main stream in the ablation period. The proportions of glacier and snow meltwater during the initial, total, and end ablation in 2016, the ablation in 2017, and the ablation in 2018 
Table 1. The correlation analysis of $\delta^{18} \mathrm{O}$ and $d$-excess and meteorological factors in the fixed point (TTH and ZMD) from 16 March to 18 July.

\begin{tabular}{|c|c|c|c|c|c|c|}
\hline & $\begin{array}{r}\text { Precipitation } \\
(\mathrm{mm})\end{array}$ & $\begin{array}{r}\text { Temperature } \\
\left({ }^{\circ}\right)\end{array}$ & $\begin{array}{r}\text { Relative humidity } \\
(\%)\end{array}$ & $\begin{array}{r}\text { Evaporation } \\
(\mathrm{mm})\end{array}$ & $\begin{array}{r}\delta^{18} \mathrm{O} \\
(\% o)\end{array}$ & $\begin{array}{r}d \text {-excess } \\
(\% o)\end{array}$ \\
\hline Precipitation (mm) & 1 & & & & & \\
\hline Temperature $\left(^{\circ}\right)$ & $0.853^{* *}$ & 1 & & & & \\
\hline Relative humidity (\%) & $0.760^{* *}$ & $0.836^{* *}$ & 1 & & & \\
\hline Evaporation (mm) & $0.658^{* *}$ & $0.865^{* *}$ & $0.586^{* *}$ & 1 & & \\
\hline$\delta^{18} \mathrm{O}(\% \circ)$ & $-0.518^{* *}$ & $-0.671^{* *}$ & $-0.555^{* *}$ & $-0.636^{* *}$ & 1 & \\
\hline$d$-excess $(\% o)$ & $0.500^{* *}$ & $0.602^{* *}$ & $0.524^{* *}$ & $0.533^{* *}$ & $-0.568^{* *}$ & 1 \\
\hline
\end{tabular}

Note: ${ }^{* *}$ correlation is significant at the 0.01 level (two-tailed).

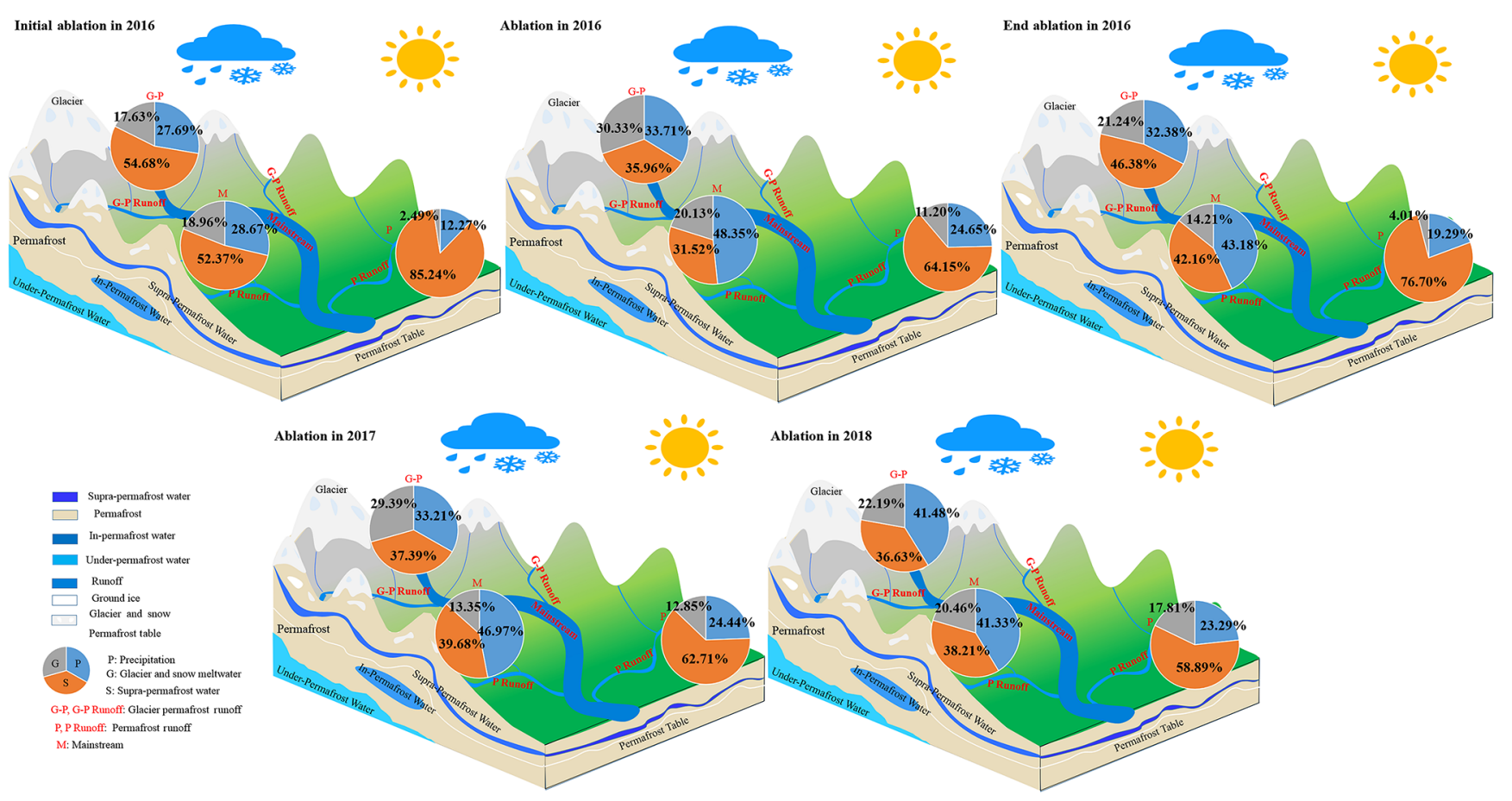

Figure 11. Conceptual model map of the recharge form and proportion of the river water in different ablation periods. (Dark green represents the basin of river in permafrost area; gray and light green represent the basin of the river in glacier permafrost area.)

were $18.96 \%, 20.13 \%, 14.21 \%, 13.35 \%$, and $20.46 \%$, respectively. The proportion of glacier and snow meltwater for the main stream $(16.59 \%)$ was higher than that for the river in the permafrost area $(3.25 \%)$ but lower than that for the river in the glacier permafrost area $(19.44 \%)$ during the initial and end ablation periods. The former proportion was also higher than that for the river in the permafrost area $(17.98 \%$ vs. $13.95 \%$ ) but lower than that for the river in the glacier permafrost area $(27.30 \%)$ during the ablation period.

The hydrological process in cold regions has one particularity. The low permeability in the permafrost layer and the freeze-thaw depths of the soil reduce soil infiltration (Wu et al., 2015; Wang et al., 2019). Therefore, the rapid replenishment of meltwater by runoff results in a difference in the runoff generation mechanism in the permafrost and non-permafrost regions (Yang et al., 2010; Li et al., 2018). Moreover, because the freeze-thaw depths of the soil change with annual fluctuations in temperature, there is an effect on soil water storage capacity that results in a difference in the runoff generation mechanism during different ablation periods (Wang et al., 2019). Wang et al. (2008) also found that the seasonal distributions and variations in rainfall runoff in the permafrost basin were controlled by the freeze-thaw process because of the impermeable nature of the freezethaw front and permafrost layer. During the initial ablation period, the supra-permafrost water - whether in the main stream, the river in the glacier permafrost area, or the river in the permafrost area - was the major recharge source. Dur- 
ing the ablation period, precipitation was the main source of runoff recharge, followed by supra-permafrost water. Although there was little difference in the proportion of precipitation and supra-permafrost water during the ablations from 2016 to 2018, precipitation was the major recharge source of runoff in this period. Supra-permafrost water was the main source of runoff recharge in the end ablation period, just as it was in the initial ablation period. In summary, runoff in the cold region during the different ablation periods was mainly composed of runoff from rainfall, meltwater, and supra-permafrost. Because of the inherent seasonal variation in precipitation, there were significant changes in precipitation during the different ablation periods. Glacier and snow meltwater was also greatly affected by climatic factors during the different ablation periods, while the supra-permafrost water was relatively stable; the latter became the main source of runoff supply, except for precipitation, in the alpine region. Thus, with the changes that the low temperatures made in the physical properties of the underlying surface, the change in the permafrost had the most significant effect on the hydrological process in cold regions.

\subsection{Hydrological significance of permafrost}

The source region of the Yangtze River is a typical permafrost area. The permafrost area is $107619.13 \mathrm{~km}^{2}$, which accounts for $77 \%$ of the total area. The seasonal frozen soil is mainly distributed in the valley area, with an area of $30754.34 \mathrm{~km}^{2}$. Field observation and research confirmed that most of the precipitation in permafrost area is frozen on the ground or used to recharge the deficit of soil water and does not directly form runoff in the permafrost area. Under the background of permafrost degradation, the area of permafrost is gradually shrinking and the thickness of permafrost is gradually decreasing with the increase in the thickness of the active layer. The degradation of ice-rich permafrost in the cold regions has an important contribution to the development of surface runoff and hot karst lakes. Due to the decrease in permafrost water storage capacity in the Qinghai Tibet Plateau, the availability of water resources will be reduced in the dry season, and the increase in water melting may lead to the increase in flood risk, and the resilience of the ecosystem will be reduced through the seasonal changes of river flow and groundwater abundance. All these changes will affect the water resource balance and sustainable development of the Qinghai Tibet Plateau, including the headwaters of major rivers in Asia, including the Yellow River, the Yangtze River, the Salween River, the Mekong River, the Brahmaputra River, the Ganges River, the Indus River, the Ili River, the Tarim River, the Erqis River, and the Yenisei River, which provide fresh water resources for the survival of about 2 billion people.

In brief, the freeze-thaw of soil in the active layer plays an important role in controlling river runoff. The increase in melting depth leads to a decrease in the direct runoff rate and slow dewatering process. The two processes of runoff retreat are the result of soil freeze-thaw in the active layer. Permafrost has two hydrological functions: on the one hand, permafrost is an impervious layer, and it has the function of preventing surface water or liquid water from infiltrating deep soil; on the other hand, it forms a soil temperature gradient, which makes the soil moist close to the ice cover. Therefore, changes in the soil water capacity, soil water permeability, and soil water conductivity, as well as the redistribution of water in the soil profile, are caused by the freeze-thaw of the active layer. The seasonal freeze-thaw process of the active layer directly leads to seasonal flow changes in surface water and groundwater, which affects surface runoff. Climate warming is the main driving force in the degradation of cold ecosystems (Wang et al., 2009, 2019; Wu et al., 2015; Li et al., 2018). More importantly, under the background of intense melting, the melting water of the cryosphere has had a significant impact on the hydrological process in the cold region. The hydrological function of groundwater in the permafrost active layer should be investigated more; in particular in the cold region where glaciers are about to subside, its hydrological function needs to be recognized. The stable isotope characteristics of the cryosphere are more complex than in other regions, and its mechanism is more complex, requiring further research.

\section{Conclusions}

Through systematical analysis of the characteristics of $\delta^{18} \mathrm{O}$, $\delta \mathrm{D}$, and $d$-excess of river water in the different ablation periods in 2016 and the ablation periods from 2016 to 2018, the results were as follows. The temporal and spatial characteristics of stable isotopes of river water were significant in the study area. The $\delta^{18} \mathrm{O}$ in the main stream was more negative than that in the glacier permafrost area river and permafrost area river. The influence of evaporation on isotope and $d$ excess is only prevalent in some places, such as the central and northern parts of the study area in the initial ablation and ablation periods. However, the influence of evaporation on isotope and $d$-excess is prevalent in most places except the southeastern part of the study area. Meanwhile, these results also indicated that there may be a hysteresis for the influence of meteorological factors on isotopes and $d$-excess. The altitude effect is only present during the ablation periods in 2016 and 2018 , and the altitude effect was $-0.16 \%$ every $100 \mathrm{~m}(p<0.05)$ and $-0.14 \%$ every $100 \mathrm{~m}(p<0.05)$. The slope of LEL for river water showed an increasing trend from initial ablation to end ablation in 2016. Meanwhile, the intercept of LEL for river water also increased from the initial ablation to the end ablation periods. Moreover, the mixed segmentation model of the end-member is used to determine the contribution proportion of different water sources to the target water. The results showed that the supra-permafrost water was the major recharge source for the permafrost area river 
in the study area. Meanwhile, the glacier and snow meltwater contributed little to the permafrost area river in the initial and end ablation periods. For the main stream, the proportion was $35.93 \%$ in the initial and end ablation periods and $45.55 \%$ in the ablation period. However, the proportion was $47.49 \%$ in the initial and end ablation periods and $36.47 \%$ in the ablation period. The proportion of glacier and snow meltwater for the main stream $(16.59 \%)$ was higher than that for the permafrost area river $(3.25 \%)$ but was lower than that for the glacier permafrost area river $(19.44 \%)$ in the initial and end ablation periods. Meanwhile, the proportion of glacier and snow meltwater for the main stream (17.98\%) was higher than that for the permafrost area river (13.95\%) but was lower than that for the glacier permafrost area river $(27.30 \%)$ in the ablation period.

Data availability. The data that support the findings of this study are available from the corresponding author upon reasonable request.

Author contributions. The main contribution for $\mathrm{ZJL}$ is writing the original draft and doing formal analysis and methodology. The main contribution for ZXL is reviewing, editing, providing conceptualization and resources, supervising, and providing the project administration. The main contribution for LLS is operating software and data curation. The main contribution for JG is investigating and data curation. The main contribution for JX is investigating and doing formal analysis. The main contribution for BJZ is investigating and data curation. The main contribution for WDG is data curation.

Competing interests. The authors declare that they have no conflict of interest.

Financial support. This research has been supported by the national "Plan of Ten Thousand People" Youth Top Talent Project, the Second Tibetan Plateau Scientific Expedition and Research Program (STEP, grant no. 2019QZKK0405), the National Key R\&D Program of China (grant no. SQ2019YFC05002401), the National Nature Science Foundation of China (grant no. 91547102), the Youth Innovation Promotion Association, CAS (grant no. 2013274), the Key Talent Project of Gansu Province (2020), and the Ecological Assessment Project of Gansu Province (2015-2020).

Review statement. This paper was edited by Fuqiang Tian and reviewed by three anonymous referees.

\section{References}

Abongwa, P. T. and Atekwana, E. A.: A laboratory study investigating the effects of dilution by precipitation on dis- solved inorganic carbon and stable isotope evolution in surface waters, Environ. Sci. Pollut. R., 25, 19941-19952, https://doi.org/10.1007/s11356-018-2085-0, 2018.

Boucher, J. L. and Carey, S. K.: Exploring runoff processes using chemical, isotopic and hydrometric data in a discontinuous permafrost catchment, Hydrol. Res., 41, 508-519, https://doi.org/10.2166/nh.2010.146, 2010.

Chang, J., Wang, G., and Mao, T.: Simulation and prediction of suprapermafrost groundwater level variation in response to climate change using a neural network model, J. Hydrol., 529, 1211-1220, https://doi.org/10.1016/j.jhydrol.2015.09.038, 2015.

Fan, Y., Chen, Y., Li, X., Li, W., and Li, Q.: Characteristics of water isotopes and ice-snowmelt quantification in the Tizinafu River, north Kunlun Mountains, Central Asia, Quatern. Int., 380, 116122, https://doi.org/10.1016/j.quaint.2014.05.020, 2015.

Halder, J., Terzer, S., Wassenaar, L. I., Araguás-Araguás, L. J., and Aggarwal, P. K.: The Global Network of Isotopes in Rivers (GNIR): integration of water isotopes in watershed observation and riverine research, Hydrol. Earth Syst. Sci., 19, 3419-3431, https://doi.org/10.5194/hess-19-3419-2015, 2015.

Hooper, R. P.: Diagnostic tools for mixing models of stream water chemistry, Water Resour. Res., 39, 1055, https://doi.org/10.1029/2002WR001528, 2003.

Gao, H., He, X., Ye, B., and Pu, J.: Modeling the runoff and glacier mass balance in a small watershed on the Central Tibetan Plateau, China, from 1955 to 2008, Hydrol. Process., 26, 15931603, https://doi.org/10.1002/hyp.8256, 2012.

Genereux, D.: Quantifying uncertainty in tracer-based hydrograph separations, Water Resour. Res., 34, 915-919, https://doi.org/10.1029/98WR00010, 1998.

$\mathrm{Gu}$, W. Z. and Longinelli, A.: A case study on the hydrological significance of stable isotope data on alpine catchments with snow cover and glaciers, Xinjiang, China, IAHS PublicationsPublications of the Inter. Asso. Hydro. Sci., 218, 371-384, 1993.

Kang, S., Zhang, Y., Qin, D., Ren, J., Zhang, Q., Grigholm, B., and Mayewski, P. A.: Recent temperature increase recorded in an ice core in the source region of Yangtze River, Chinese Sci. Bull., 52, 825-831, https://doi.org/10.1007/s11434-007-0140-1, 2007.

Klaus, J. and McDonnell, J. J.: Hydrograph separation using stable isotopes: Review and evaluation, J. Hydrol., 505, 47-64, https://doi.org/10.1016/j.jhydrol.2013.09.006, 2013.

Kong, Y. and Pang, Z. : Evaluating the sensitivity of glacier rivers to climate change based on hydrograph separation of discharge, J. Hydrol., 434, 121-129, https://doi.org/10.1016/j.jhydrol.2012.02.029, 2012.

Lafrenière, M. J. and Lamoureux, S. F.: Effects of changing permafrost conditions on hydrological processes and fluvial fluxes, Earth-Sci. Rev., 191, 212-223, https://doi.org/10.1016/j.earscirev.2019.02.018, 2019.

Li, C., Yang, S., Lian, E., Yang, C., Deng, K., and Liu, Z.: Damming effect on the Changjiang (Yangtze River) river water cycle based on stable hydrogen and oxygen isotopic records, J. Geochem. Explor., 165, 125-133, https://doi.org/10.1016/j.gexplo.2016.03.006, 2016.

Li, Z. X., Qi, F., Liu, W., Wang, T. T., Cheng, A. F., Yan, G., Guo, X. Y., Pan, Y. H., Li, J. G., Guo, R., and Jia, B.: Study on the contribution of cryosphere to runoff in the cold alpine basin: A case study of Hulugou River Basin in 
the Qilian Mountains, Global Planet. Change, 122, 345-361, https://doi.org/10.1016/j.gloplacha.2014.10.001, 2014a.

Li, Z. X., Qi, F., Wei, L., Tingting, W., Yan, G., Yamin, W., Cheng, A. F., Li, J. G., and Liu, L.: Spatial and temporal trend of potential evapotranspiration and related driving forces in Southwestern China, during 1961-2009, Quatern. Int., 336, 127-144, https://doi.org/10.1016/j.quaint.2013.12.045, 2014 b.

Li, Z. X., Qi, F., Wang, Q. J., Song, Y., Aifang, C., and Jianguo, L.: Contribution from frozen soil meltwater to runoff in an in-land river basin under water scarcity by isotopic tracing in northwestern China, Global Planet. Change, 136, 41-51, https://doi.org/10.1016/j.gloplacha.2015.12.002, 2016a.

Li, Z. X., Qi, F., Zongjie, L., Ruifeng, Y., Juan, G., and Yuemin, L.: Climate background, fact and hydrological effect of multiphase water transformation in cold regions of the Western China: A review, Earth-Sci. Rev., 190, 33-57, https://doi.org/10.1016/j.earscirev.2018.12.004, 2018.

Li, Z. X., Qi, F., Wang, Q. J., Song, Y., Jianguo, L., Yongge, L., and Yamin, W.: Quantitative evaluation on the influence from cryosphere meltwater on runoff in an inland river basin of China, Global Planet. Change, 143, 189-195, https://doi.org/10.1016/j.gloplacha.2016.06.005, 2016b.

Li, Z. X., Qi, F., Liu, W., Wang, T. T., Guo, X. Y., Li, Z. J., Gao, Y., Pan, Y. H., Guo, R., Jia, B., Song, Y. X., and Han, C. T.: The stable isotope evolution in Shiyi glacier system during the ablation period in the north of Tibetan Plateau, China, Quaternary Int., 380, 262-271, https://doi.org/10.1016/j.quaint.2015.02.013, 2015.

Li, Z., Yuan, R., Feng, Q., Zhang, B., Lv, Y., Li, Y., Wei, W., Chen, W., Ning, T. T., Gui, J., and Shi, Y.: Climate background, relative rate, and runoff effect of multiphase water transformation in Qilian Mountains, the third pole region, Sci. Total Environ., 663, 315-328, https://doi.org/10.1016/j.scitotenv.2019.01.339, 2019.

Li, Z. J., Song, L. L., Jing-zhu, M., and Li, Y. G.: The characteristics changes of $\mathrm{pH}$ and $\mathrm{EC}$ of atmospheric precipitation and analysis on the source of acid rain in the source area of the Yangtze River from 2010 to 2015, Atmos. Environ., 156, 61-69, https://doi.org/10.1016/j.atmosenv.2017.02.025, 2017.

Li, Z. J., Zong-Xing, L., Ling-Ling, S., Jin-Zhu, M., and Yong, S.: Environment significance and hydrochemical characteristics of supra-permafrost water in the source region of the Yangtze River, Sci. Total Environ., 644, 1141-1151, https://doi.org/10.1016/j.scitotenv.2018.07.029, 2018.

Liang, E., Shao, X., and Qin, N.: Tree-ring based summer temperature reconstruction for the source region of the Yangtze River on the Tibetan Plateau, Global Planet. Change, 61, 313-320, https://doi.org/10.1016/j.gloplacha.2007.10.008, 2008.

Liu, F., Williams, M. W., and Caine, N.: Source waters and flow paths in an alpine catchment, Colorado Front Range, United States, Water Resour. Res., 40, 1-17, https://doi.org/10.1029/2004WR003076, 2004.

Lutz, A. F., Immerzeel, W. W., Shrestha, A. B., and Bierkens, M. F. P.: Consistent increase in High Asia's runoff due to increasing glacier melt and precipitation, Nat. Clim. Change, 4, 587, https://doi.org/10.1038/nclimate2237, 2014.

Maurya, A. S., Shah, M., Deshpande, R. D., Bhardwaj, R. M., Prasad, A., and Gupta, S. K.: Hydrograph separation and precipitation source identification using stable water isotopes and conductivity: River Ganga at Himalayan foothills, Hydrol. Process., 25, 1521-1530, https://doi.org/10.1002/hyp.7912, 2011.

Mu, Y., Ma, W., Li, G., Niu, F., Liu, Y., and Mao, Y.: Impacts of supra-permafrost water ponding and drainage on a railway embankment in continuous permafrost zone, the interior of the Qinghai-Tibet Plateau, Cold Reg. Sci. Technol., 154, 23-31, https://doi.org/10.1016/j.coldregions.2018.06.007, 2018.

Pan, X., Yu, Q., You, Y., Chun, K. P., Shi, X., and Li, Y.: Contribution of supra-permafrost discharge to thermokarst lake water balances on the northeastern Qinghai-Tibet Plateau, J. Hydrol., 555, 6210-630, https://doi.org/10.1016/j.jhydrol.2017.10.046, 2017.

Prasch, M., Mauser, W., and Weber, M.: Quantifying present and future glacier melt-water contribution to runoff in a central Himalayan river basin, The Cryosphere, 7, 889-904, https://doi.org/10.5194/tc-7-889-2013, 2013.

Pu, T., He, Y., Zhu, G., Zhang, N., Du, J., and Wang, C.: Characteristics of water stable isotopes and hydrograph separation in Baishui catchment during the wet season in Mt. Yulong region, south western China, Hydrol. Process., 27, 3641-3648, https://doi.org/10.1002/hyp.9479, 2013.

$\mathrm{Pu}$, J.: Glacier Inventory of China: The Yangtze River Drainage Basin, Gansu Culture Press, Lanzhou, 1-81, 1994.

Qu, J., Lu, S., Gao, Z., Li, W., Li, Z., and Yu, F.: Research on Hydrogeochemical Characteristics and Transformation Relationships between Surface Water and Groundwater in the Weihe River, Hydrol. Earth Syst. Sci. Discuss., https://doi.org/10.5194/hess2017-654, 2017.

Shi, Y., Niu, F., Lin, Z., and Luo, J.: Freezing/thawing index variations over the circum-Arctic from 1901 to 2015 and the permafrost extent, Sci. Total Environ., 660, 1294-1305, https://doi.org/10.1016/j.scitotenv.2019.01.121, 2019.

Uhlenbrook, S. and Hoeg, S.: Quantifying uncertainties in tracer-based hydrograph separations: a case study for two, three- and five-component hydrograph separations in a mountainous catchment, Hydrol. Process., 17, 431-453, https://doi.org/10.1002/hyp.1134, 2003.

Wang, G., Liu, G., and Liu, L. A.: Spatial scale effect on seasonal streamflows in permafrost catchments on the Qinghai-Tibet Plateau, Hydrol. Process., 26, 973-984, https://doi.org/10.1002/hyp.8187, 2012.

Wang, G., Hu, H., and $\mathrm{Li}$, T.: The influence of freezethaw cycles of active soil layer on surface runoff in a permafrost watershed, J. Hydrol., 375, 438-449, https://doi.org/10.1016/j.jhydrol.2009.06.046, 2009.

Wang, G., Tianxu, M., Juan, C., Chunlin, S., and Kewei, H.: Processes of runoff generation operating during the spring and autumn seasons in a permafrost catchment on semi-arid plateaus, J. Hydrol., 550, 307-317, https://doi.org/10.1016/j.jhydrol.2017.05.020, 2017.

Wang, G., Yuanshou, L., Yibo, W., and Qingbo, W.: Effects of permafrost thawing on vegetation and soil carbon pool losses on the Qinghai-Tibet Plateau, China, Geoderma, 143, 143-152, https://doi.org/10.1016/j.geoderma.2007.10.023, 2008.

Wang, T., Wu, T., Wang, P., Li, R., Xie, C., and Zou, D.: Spatial distribution and changes of permafrost on the QinghaiTibet Plateau revealed by statistical models during the period of 1980 to 2010, Sci. Total Environ., 650, 661-670, https://doi.org/10.1016/j.scitotenv.2018.08.398, 2019. 
Wang, X., Chen, R., Liu, G., Yang, Y., Song, Y., Liu, J., Liu, Z. W., Han, C. T., Liu, X. J., Guo, S. H., and Wang, L.: Spatial distributions and temporal variations of the near-surface soil freeze state across China under climate change, Global Planet. Change, 172, 150-158, https://doi.org/10.1016/j.gloplacha.2018.09.016, 2019.

Wu, Q., Hou, Y., Yun, H., and Liu, Y.: Changes in activelayer thickness and near-surface permafrost between 2002 and 2012 in alpine ecosystems, Qinghai-Xizang (Tibet) Plateau, China, Global Planet. Change, 124, 149-155, https://doi.org/10.1016/j.gloplacha.2014.09.002, 2015.

Yang, L., Song, X., Zhang, Y., Han, D., Zhang, B., and Long, D.: Characterizing interactions between surface water and groundwater in the Jialu River basin using major ion chemistry and stable isotopes, Hydrol. Earth Syst. Sci., 16, 4265-4277, https://doi.org/10.5194/hess-16-4265-2012, 2012.

Yang, M., Nelson, F. E., Shiklomanov, N. I., Guo, D., and Wan, G.: Permafrost degradation and its environmental effects on the Tibetan Plateau: A review of recent research, Earth-Sci. Rev., 103, 31-44, https://doi.org/10.1016/j.earscirev.2010.07.002, 2010.

Yao, Z., Liu, Z., Huang, H., Liu, G., and Wu, S.: Statistical estimation of the impacts of glaciers and climate change on river runoff in the headwaters of the Yangtze River, Quatern. Int., 336, 89-97, https://doi.org/10.1016/j.quaint.2013.04.026, 2014. mm, respectively.
Yu, G. A., Liu, L., Li, Z., Li, Y., Huang, H., Brierley, G., Brendon, B., Wang, Z. Y., and Pan, B. Z.: Fluvial diversity in relation to valley setting in the source region of the Yangtze and Yellow Rivers, J. Geogr. Sci., 23, 817-832, https://doi.org/10.1007/s11442-013-1046-2, 2013.

Yu, G. A., Brierley, G., Huang, H. Q., Wang, Z., Blue, B., and Ma, Y.: An environmental gradient of vegetative controls upon channel planform in the source region of the Yangtze and Yellow Rivers, Catena, 119, 143-153, https://doi.org/10.1016/j.catena.2014.02.010, 2014.

Zhu, X., Wu, T., Zhao, L., Yang, C., Zhang, H., Xie, C., Li, R., Wang, W. H., Hu, G. J., Ni, J., Du, Y. Z., Yang, S. H., Zhang, Y. X., Hao, J. M., Yang, C., Qiao, Y. P., Shi, J. Z., and Du, Y.: Exploring the contribution of precipitation to water within the active layer during the thawing period in the permafrost regions of central Qinghai-Tibet Plateau by stable isotopic tracing, Sci. Total Environ., 661, 630-644, https://doi.org/10.1016/j.scitotenv.2019.01.064, 2019. 